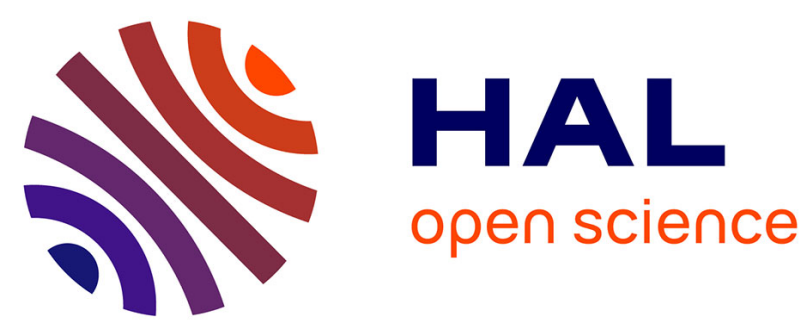

\title{
New insights into SMOS sea surface salinity retrievals in the Arctic Ocean
}

\author{
Alexandre Supply, Jacqueline Boutin, Jean-Luc Vergely, Nicolas N. \\ Kolodziejczyk, Gilles Reverdin, Nicolas Reul, Anastasiia Tarasenko
}

\section{- To cite this version:}

Alexandre Supply, Jacqueline Boutin, Jean-Luc Vergely, Nicolas N. Kolodziejczyk, Gilles Reverdin, et al.. New insights into SMOS sea surface salinity retrievals in the Arctic Ocean. Remote Sensing of Environment, 2020, 249, pp.112027. 10.1016/j.rse.2020.112027 . hal-02959141

\section{HAL Id: hal-02959141 \\ https://hal.sorbonne-universite.fr/hal-02959141}

Submitted on 6 Oct 2020

HAL is a multi-disciplinary open access archive for the deposit and dissemination of scientific research documents, whether they are published or not. The documents may come from teaching and research institutions in France or abroad, or from public or private research centers.
L'archive ouverte pluridisciplinaire HAL, est destinée au dépôt et à la diffusion de documents scientifiques de niveau recherche, publiés ou non, émanant des établissements d'enseignement et de recherche français ou étrangers, des laboratoires publics ou privés. 


\section{New insights into SMOS Sea Surface Salinity retrievals in the Arctic Ocean.}

2 Alexandre Supply ${ }^{1}$, Jacqueline Boutin ${ }^{1}$, Jean-Luc Vergely $^{2}$, Nicolas Kolodziejczyk ${ }^{3}$, Gilles 3 Reverdin $^{1}$, Nicolas Reul ${ }^{3}$ and Anastasiia Tarasenko ${ }^{3,4}$.

${ }^{1}$ LOCEAN-IPSL, Sorbonne Université-CNRS-IRD-MNHN, Paris, France

$6 \quad{ }^{2}$ ACRI-St, Guyancourt, France

7 32Laboratoire d'Océanographie Physique et Spatiale (LOPS), Univ. Brest, CNRS, Ifremer, IRD, 8 Brest, France

$9 \quad{ }^{4}$ Arctic and Antarctic Research Institute, Saint-Petersburg, Russia

$\underline{\text { Abstract }}$

Since 2010, the Soil Moisture and Ocean Salinity (SMOS) satellite mission monitors the earth emission at L-Band. It provides the longest time series of Sea Surface Salinity (SSS) from space over the global ocean. However, the SSS retrieval at high latitudes is a challenge because of the low sensitivity L-Band radiometric measurements to SSS in cold waters and to the contamination of SMOS measurements by the vicinity of continents, of sea ice and of Radio Frequency Interferences. In this paper, we assess the quality of weekly SSS fields derived from swath-ordered instantaneous SMOS SSS (so called Level 2) distributed by the European Space Agency. These products are filtered according to new criteria. We use the pseudo-dielectric constant retrieved from SMOS brightness temperatures to filter SSS pixels polluted by sea ice. We identify that the dielectric constant model and the sea surface temperature auxiliary parameter used as prior information in the SMOS SSS retrieval induce significant systematic errors at low temperatures. We propose a novel empirical correction to mitigate those sources of errors at high latitudes. 
Comparisons with in-situ measurements ranging from 1 to $11 \mathrm{~m}$ depths spotlight huge vertical stratification in fresh regions. This emphasizes the need to consider in-situ salinity as close as possible to the sea surface when validating L-band radiometric SSS which are representative of the first top centimeter.

SSS Standard deviation of differences (STDD) between weekly SMOS SSS and in-situ near surface salinity significantly decrease after applying the SSS correction, from 1.46 pss to 1.28 pss. The correlation between new SMOS SSS and in-situ near surface salinity reaches 0.94 . SMOS estimates better capture SSS variability in the Arctic Ocean in comparison to TOPAZ reanalysis (STDD between TOPAZ and in-situ SSS $=1.86 \mathrm{pss}$ ), particularly in river plumes with very large SSS spatial gradients.

\section{Introduction}

In the context of global warming, Arctic is experiencing an increase of temperature two to three times higher than the global mean average (IPCC, 2018). The freshwater cycle in that region is profoundly modified. The salinity is decreasing (see a review in Carmack et al., 2016) except in the Barents Sea where both temperature and salinity are increasing under the effect of 'Atlantification', i.e. increase of salty supply from North Atlantic waters (Lind et al., 2018). Eventually, in the Arctic Ocean, salinity is the key dynamical variable, ensuring the stability of the water column and controlling the ocean circulation (Carmack., 2007).

The high variability of freshwater inputs is a dominant feature of the Arctic Ocean and induces a large variability in salinity (Carmack et al., 2015; Haine et al., 2015). In addition to the seasonal freshwater input from ice melting, the Arctic Ocean sea surface salinity (SSS) is mainly controlled by numerous river inputs. The Arctic Ocean covers only $1.2 \%$ of the global ocean but collects $11 \%$ of the freshwater from global river plumes (Shiklomanov et al., 1998) mainly in the interior shelves of the Kara, Laptev and East-Siberian Seas. In addition, the surface water entering poleward through Bering Strait is rather fresh in comparison with salty 
waters from Atlantic. The third major net source of freshwater in the Arctic Ocean comes from air-sea exchange (precipitation minus evaporation). Freshwater is exported equatorward from the Arctic Ocean at Fram Strait, over the east Greenland shelves, as well as through Davis Strait after crossing Baffin Bay.

Since 2010, L-Band radiometer satellite missions (SMOS (2010-present), Kerr et al., 2010, Font et al., 2010), Aquarius (2011-2015, Lagerloef et al., 2013) and SMAP (2015-present, Piepmeier et al., 2017) have demonstrated their abilities to monitor salinity variability at various temporal and spatial scales in synergy with in-situ measurements as reviewed by Vinogradova et al. (2019) and Reul et al. (2020). L-Band radiometry is of particular interest in the Arctic Ocean as it combines the ability to retrieve thin sea ice thickness and salinity. SMOS is the first satellite mission carrying an L-band radiometer (the MIRAS interferometer) allowing to retrieve SSS with an unprecedented temporal coverage. It follows a sun-synchronous circular orbit.

L-Band radiometer measurements are significantly less sensitive to SSS in cold water than in warm tropical conditions (Meissner et al., 2016). However, a very large range of SSS is observed in the Arctic, with salinity close to 0pss in river plumes and reaching 35 pss in the Atlantic water (Carmack et al., 2015). For this reason, L-Band radiometry remains valuable for the detection of large SSS variability and the monitoring of oceanic fronts in the Arctic Ocean (Brucker et al. 2014; Matsuoka et al., 2016; Olmedo et al., 2018; Tang et al., 2018; Tarasenko et al. 2019).

Brucker et al. (2014) and Tang et al (2018) presented capabilities (monitoring of the river plumes and of upper layer freshwater exchanges between different Arctic Seas and sub-Arctic Oceans) and limits (sea-ice presence) of L-Band SSS retrievals based on Aquarius and SMAP measurements respectively. Köhler et al. (2015) found sea surface temperature (SST) - related bias (-1.2 pss) of SMOS SSS retrieved in cold waters and pollution due to Radio Frequency 
Interference (RFI) in the northern North Atlantic. Matsuoka et al. (2016) used SMOS SSS monitoring together with ocean color remote sensing in order to detect the origin (river or ice melting) of salinity interannual anomalies close to the Mackenzie river mouth. Tarasenko et al. (2019) showed the atmospheric influence on the river plume variability in the Laptev Sea at intra-seasonal time scale (a few weeks) based on SMOS SSS. Recently, an SSS retrieval methodology alternative to the one in place in the ESA L2 chain has been proposed with new systematic bias corrections and filtering adjusted to the Arctic Ocean conditions (Olmedo et al., 2018).

Using an accurate SST is critical in order to retrieve SSS with a minimum uncertainty. For instance, at $\mathrm{SST}=5^{\circ} \mathrm{C}$ and $\mathrm{SSS}=35 \mathrm{pss}$, an error of $1^{\circ} \mathrm{C}$ roughly leads to an error of $0.1 \mathrm{~K}$ in brightness temperature (TB), which translates into in error of 0.3 pss in the retrieved SSS (Yueh et al., 2001). According to Stroh et al (2015) and Høyer et al (2012), systematic differences of various space-based SST measurements in the Arctic Ocean, estimated by comparisons with buoys and ship-based measurements, range from 0.3 to $0.5^{\circ} \mathrm{C}$ depending on the season and on the sensor. The temporal and spatial resolution of the SST fields obtained by different optimal analyses vary significantly. This results in significant differences in the estimated SST over highly dynamical and variable regions such as river plumes. A satellite SSS bias related to SST may also be due to flaws in the dielectric constant model that links TB to SSS and SST (Dinnat et al., 2019). The presence of badly detected sea ice can also lead to negative bias on the retrieved SSS (Tang et al., 2018).

The satellite SSS validation is made difficult because of the strong vertical haline stratification observed in the upper Arctic Ocean waters, as L-band radiometer only senses the top centimeter of the ocean (Boutin et al., 2016) and most in-situ sensors probe salinity much deeper (meters). This stratification varies geographically and temporally. The depth of the 
mixed layer (ML) may be shallower than $10 \mathrm{~m}$ in summer in some regions such as the Beaufort

100 Sea (Peralta-Ferriz et al., 2015).

101 This paper focuses on validating weekly fields derived from the European Space Agency

102 (ESA) SMOS level 2 (L2) SSS, analyzing potential sources of errors and proposing

103 improvements. A description of the data and methods is first given (section 2 and 3). The

104 influence of stratification on the SSS validation is then investigated (section 4). A first

105 correction of SSS is derived using the pseudo dielectric constant parameter retrieved by the

106 SMOS ESA L2 processing (Waldteufel et al., 2004). The influence of the prior SST on SSS

107 retrieval is further analyzed (section 5). Finally, corrected SMOS weekly SSS are compared

108 against surface salinity from TOPAZ reanalysis and in situ measurements from vessels transect

109 to assess the product content from short to interannual time scales (section 6).

110

111 2. Data

$112 \quad$ 2.1. Satellite related parameters

113 2.1.1. SST

114 In the SMOS L2 SSS processor, SST provided by European Centre for Medium-Range

115 Weather Forecasts (ECMWF) Integrated Forecasting System (SST ECMWF$_{\text {) }}$ are used as priors in

116 the SSS retrievals. These forecasts are initialized 6 to 12 hours before by OSTIA SST (Donlon

117 et al., 2012; ECMWF, 2016). The OSTIA SST analysis is generated using a multiscale

118 interpolation of various satellite SST (infrared and microwave SST) and in-situ measurements

119 at a grid spacing close to $5 \mathrm{~km}$.

120 In this paper, we compare $\mathrm{SST}_{\mathrm{ECMWF}}$ with the $9 \mathrm{~km}$ grid resolution infrared and microwave

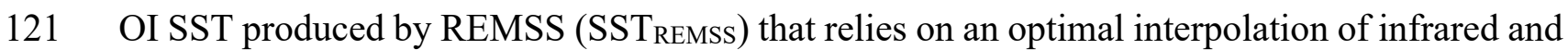

microwave

measurements,

but

no

in-situ

measurements 
124 influence of the SST differences onto the retrieved SSS is estimated as described in section 5.3.

\subsubsection{SMOS L2 SSS and Acard}

We use the SMOS L2 SSS (uncorrected for Land Sea Contamination) v662 distributed by ESA from 2011 to 2017 in the region bounded by latitude $60^{\circ} \mathrm{N}$ and $90^{\circ} \mathrm{N}$. These products are organized in $1 / 2$ orbits of instantaneous SSS retrievals. The principle of the ESA L2 SMOS SSS retrieval is recalled in (Boutin et al., 2018; section 3.1 and documents cited herein). SSS are oversampled over an Icosahedral Snyder Equal Area (ISEA) grid at $15 \mathrm{~km}$ resolution but the mean spatial resolution of ESA L2 SMOS SSS is close to $50 \mathrm{~km}$. The dielectric constant model of sea water used in the SMOS processor is the Klein and Swift (1977) model (hereafter $\mathrm{KS})$.

We also use the pseudo dielectric constant (Acard) parameter. Acard is an effective Lband dielectric constant retrieved from $\sim$ hundreds SMOS multi-angular TB, independent of any SSS or dielectric constant model assumption. It was designed to integrate all available information about surface dielectric characteristics (Waldteufel et al. 2004). Acard allows to synthesize in one parameter the information on the dielectric constant that is contained in all SMOS TB. Since the noise on individual TB is large $(2-3 \mathrm{~K})$, Acard synthesis allows a more precise filtering than a filtering applied on each individual TB. SMOS SSS and Acard are retrieved using a Bayesian approach through the minimization of the $\chi^{2}$ cost function:

$$
\chi^{2}=\sum_{n=1}^{N} \frac{\left[T b_{n}^{\text {meas }}-T b_{n}^{\text {mod }}\left(\theta_{n}, P_{i} \ldots\right)\right]^{2}}{\sigma_{T b n}^{2}}+\sum_{n=1}^{M} \frac{\left[P_{i}-P_{i 0}\right]^{2}}{\sigma_{P i 0}^{2}}
$$

where $N$ is the number of measurements available for retrievals in vertical and horizontal polarizations at different incidence angles $\theta_{n}, P_{\mathrm{i}}$ are prior parameters, $T b^{\text {meas }}$ are measured TB corrected for some phenomena, $T b^{\bmod }$ are modelled TB. These various components are described for each retrieval in Table 1. Retrievals are initialized with European Centre for Medium-Range Weather Forecasts (ECMWF) (wind speed (WS $\mathrm{ECMWF}_{\text {), SST }}$ 
$\left.148\left(\mathrm{SST}_{\mathrm{ECMWF}}\right)\right)$. In case of SSS retrieval, both wind speed $\left(\mathrm{WS}_{\mathrm{L} 2}\right)$ and $\mathrm{SST}\left(\mathrm{SST}_{\mathrm{L} 2}\right)$ are retrieved together with SMOS SSS ( $\left.\mathrm{SSS}_{\mathrm{L} 2}\right)$. In case of Acard retrieval (Acard $\left.\mathrm{L} 2_{2}\right)$ only SST (SST $\left.\mathrm{ACARD}\right)$

150 is retrieved together with Acard. A detailed description of the Acard retrieval in the L2 Ocean

151 Salinity processor is given in appendix-A.

152 Acard as simulated with KS sea water dielectric constant and ice dielectric constant

153 reported in (Ulaby, 1990), varies from approximately 50 in pixels totally covered with sea water

154 to a value close to 0 in pixels totally covered by ice. Hence, pixels partially covered by sea ice

155 exhibit lower Acard values than pure water pixels.

156 Table 1: Summary of SMOS SSS and Acard retrieval principle in the SMOS L2OS processor.

\begin{tabular}{|c|c|c|}
\hline & $\underline{\text { SSS retrieval }}$ & Acard retrieval \\
\hline$\underline{\text { Modeled TBs }}$ & $\begin{array}{l}\text { Dielectric constant, wind, } \\
\text { galactic, atmospheric model } \\
\text { components }\end{array}$ & Flat sea emission \\
\hline$\frac{\text { Measured }}{\underline{\text { TBs }}}$ & SMOS multi-angular TBs & $\begin{array}{l}\text { SMOS multi-angular TBs corrected from } \\
\text { wind, galactic and atmospheric model } \\
\text { components }\end{array}$ \\
\hline $\begin{array}{c}\text { Prior } \\
\text { variables }\end{array}$ & $\mathrm{WS}_{\mathrm{ECMWF}}, \mathrm{SST}_{\mathrm{ECMWF}}$ & $\mathrm{SST}_{\mathrm{ECMWF}}$ \\
\hline $\begin{array}{l}\text { Retrieved } \\
\text { variables }\end{array}$ & $\mathrm{SSS}_{\mathrm{L} 2}, \mathrm{WS}_{\mathrm{L} 2}, \mathrm{SST}_{\mathrm{L} 2}$ & Acard $_{\mathrm{L} 2}, \mathrm{SST}_{\text {Acard }}$ \\
\hline
\end{tabular}




\subsubsection{Pre-processed SMOS L3 maps}

Level 3 (L3) 7-day moving averages of SMOS ESA L2 parameters are produced each day. The 15-km ISEA grid is kept from L2 to L3, in order to avoid spatial smoothing. Only pixels further than $40 \mathrm{~km}$ from land are considered. Each SSS or Acard entering the 7-day average is weighted by a Gaussian weight function with a 3-day standard deviation and by the L2 uncertainty taken as the L2 SSS theoretical error multiplied by the $\chi^{2}$ value (L2 SSS error and $\chi^{2}$ estimates are described in Boutin et al., 2018). Level 2 products' flags raised for strong sunglint ('Dg_sun_glint_fov'), moonglint ('Dg_moonglint'), or galactic glints ('Dg_galactic_Noise_Error') are filtered out. L2 measurements for which WS $\mathrm{ECMWF}_{\mathrm{E}}$ is lower than $3 \mathrm{~m} \cdot \mathrm{s}^{-1}$ or greater than $12 \mathrm{~m} \cdot \mathrm{s}^{-1}$ are not considered due to larger uncertainties with the roughness model for these ranges of wind speed. L3 SSS uncertainty is estimated through an error propagation of L2 SSS uncertainty estimates.

Frequent revisit of polar areas by SMOS allows typically between 0 and 50 L2 retrievals in each pixel within 7 days. We remove L3 pixels with less than five L2 retrievals and with an average distance to the center of the SMOS track higher than $200 \mathrm{~km}$ in order to minimize the influence of uncertain measurements at the edge of the swath. We name $\mathrm{SSS}_{\mathrm{SMOS}}$ the SMOS SSS obtained after this processing.

\subsection{Model reanalysis}

We use ARCTIC_REANALYSIS_PHYS_002_003 distributed by the Copernicus Marine Environment Monitoring Service (CMEMS). This product is based on the TOPAZ system in its version 4 (Sakov et al., 2012) that uses the HYCOM model (Chassignet et al., 2009). The TOPAZ reanalysis ingests various in-situ and satellite measurements in order to provide fields of temperature, salinity, sea ice drift or sea ice concentration. Salinity measured by Argo floats and some research cruises are assimilated. TOPAZ does not assimilate SMOS SSS. 
183 Atlas climatology (WOA05) and Polar Science Center Hydrographic Climatology (PHC 184 version 3.0). In addition to the initialization, a climatology of river runoff is used in order to 185 resolve remaining inaccuracies in evaporation and run-off (CMEMS Arctic Ocean Physical 186 Reanalysis Product User Manual). The river discharge monthly climatology is derived using 187 the Total Runoff Integrating Pathways (TRIP, Oki and Sud., 1998) and run-offs estimates from 188 ERA-interim. SMOS SSS are compared with TOPAZ surface salinity simulated at 0m depth 189 (SSS Topaz). We also used Sea Ice Concentration (SIC) from TOPAZ reanalysis in order to study 190 the influence of sea ice on SMOS SSS.

191 2.3. In-situ measurements

192 Satellite L3 parameters are collocated with in situ measurements described below using a 193 nearest neighbor criteria.

\subsubsection{Argo profilers}

196 (Global Data Argo Center, http: //www.coriolis.eu.org/). Only measurements flagged as good 197 (flag 1), between 1 and $10 \mathrm{~m}$ depth are used.

198 Argo floats are mainly located in the North Atlantic Ocean between $60^{\circ} \mathrm{W}$ and $20^{\circ} \mathrm{E}$ 199 (Figure 1A), with a few floats in the Chukchi Sea. This spatial distribution results in a very 200 peaky salinity distribution, with a salinity mode close to 35 pss and very few salinities below 20134 pss (Figure 1D). 

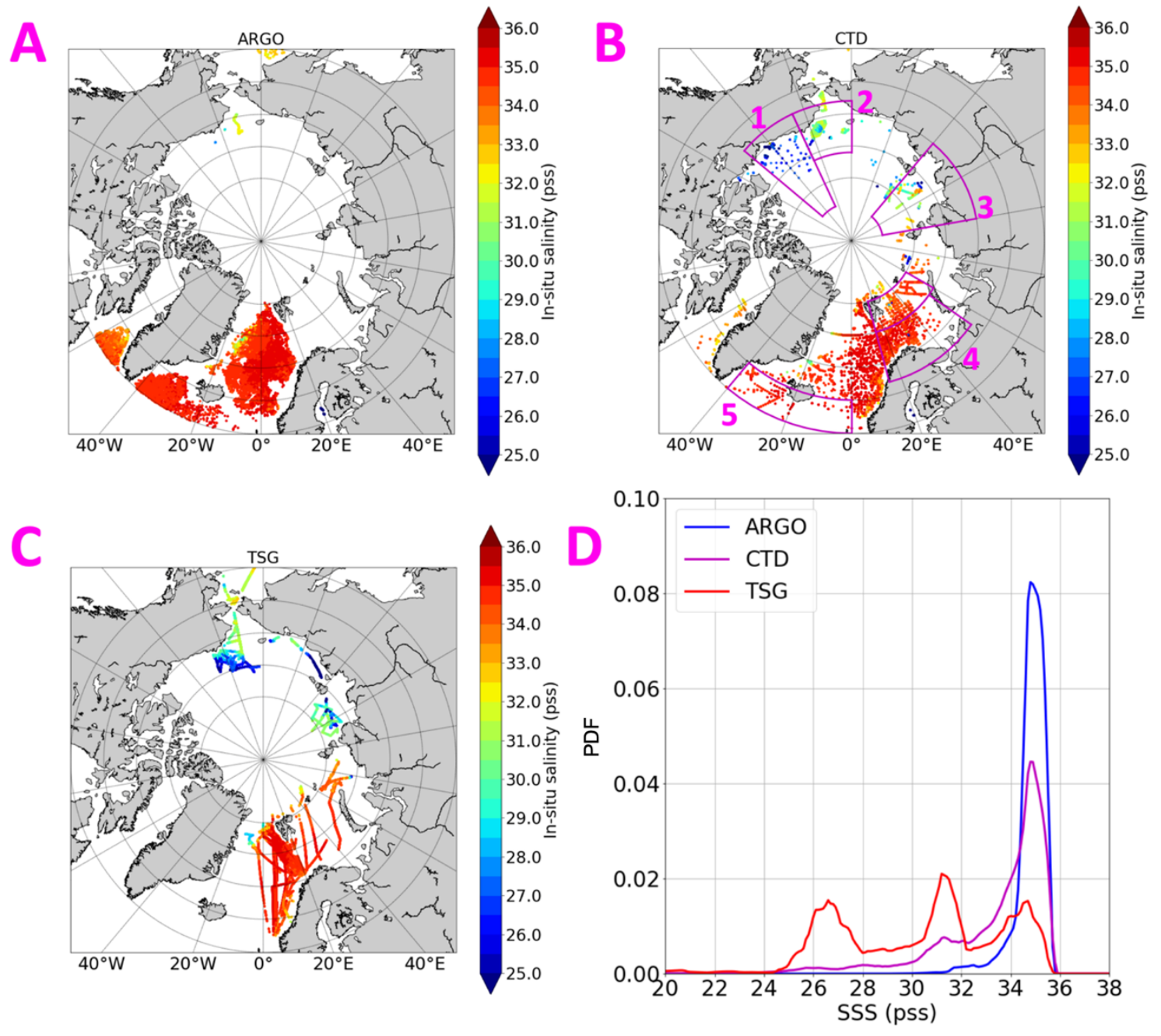

Figure 1: In-Situ near-surface salinity measured at the location of (A) Argo floats (B) CTD casts in different study areas (1 - Beaufort Sea, 2 - Chukchi Sea, 3 - Laptev Sea, 4 - Barents Sea, 5 - Atlantic area) and (C) underway TSG. (D) Probability density function (PDF) of salinity observed with the different devices.

\subsubsection{CTD profiles}

A large part of the CTD profiles is downloaded from the Coriolis data center. We also consider CTD profiles:

- from two NABOS cruises, in 2013 (Ivanov et al., 2013) and 2015 (Polyakov et al., 2015), in the Kara Sea, Laptev Sea and East-Siberian Sea; 
- from the Arctic Floating University collected in 2012 (Makhotin and Ivanov, 2018a), 2013 (Makhotin and Ivanov, 2018b) and 2014 (Makhotin and Ivanov, 2018c) in the Barents Sea,

- collected in the Laptev Sea and East-Siberian Sea during Swerus C-3 cruise (Björk, 2017);

- in the Beaufort Sea from the Beaufort Gyre Exploration Project website (https://www.whoi.edu/website/beaufortgyre/home).

Only measurements between 1 and $10 \mathrm{~m}$ are considered. We noticed a few CTD 216 erroneous measurements. In order to ensure that suspicious measurements are not considered in the validation, we apply a $3 \sigma$-filtering with respect to $\mathrm{SSS}_{\mathrm{TOPAZ}}$ (see section 2.3; only in-situ measurements with an absolute difference between $\mathrm{S}_{\mathrm{in}-\text { situ }}$ and $\mathrm{SSS}_{\mathrm{TOPAZ}}$ lower than $3 \sigma(5.85 \mathrm{pss})$ are kept).

CTD casts in the Arctic Ocean cover a larger range of temperature and salinity than Argo (Figure 1B, 1D). Indeed, the CTD dataset samples very low salinity areas in the Arctic Ocean in the Beaufort gyre or river plumes, as for example in the Laptev Sea or East-Siberian Sea. the R/V Polarstern, the R/V Mirai and the S/V Tara. Data of R/V Heincke and R/V Polarstern are downloaded on PANGAEA website (https://www.pangaea.de) and listed in the AppendixB. R/V Mirai data of the year 2012 (JAMSTEC, 2015a), 2013 (JAMSTEC, 2015b) and 2014 (JAMSTEC, 2018) are downloaded on the DARWIN website of JAMSTEC 230 (http://www.godac.jamstec.go.jp/darwin/e). S/V Tara measurements, that were quality checked 231 at LOCEAN, are available on the Coriolis website. TSG measurements are taken at different depths, from $1 \mathrm{~m}$ on $\mathrm{S} / \mathrm{V}$ Tara to $11 \mathrm{~m}$ for $\mathrm{R} / \mathrm{V}$ Polarstern. 
Underway TSGs salinities are the most variable (Figure 1C). Their statistical distribution is characterized by three modes, a first mode is between 34 and 36 pss, a second mode between 31 and 32 pss and, finally, a third mode between 25 and 27 pss. Underway TSGs have a similar geographical sampling as CTD casts but with more measurements closer to coast and a better sampling of river plumes.

3. Influence of salinity vertical stratification on satellite/in-situ comparisons

3.1. Depth dependency: case of CTD profiles

We analyzed the effect of stratification on the differences between in-situ salinity ( $\left.\mathrm{S}_{\text {insitu }}\right)$ and $\mathrm{SSS}_{\mathrm{SMOS}}$. Figure 2 presents the effect of stratification on mean comparisons between $\mathrm{S}_{\text {insitu }}$ and $\mathrm{SSS}_{\mathrm{SMOS}}$ considering different depths. We consider here only CTD casts which provide the most complete depth and spatial coverage in the studied areas. Two cases are examined : cases with a difference lower than -0.1 pss between shallower (salinity average from $1 \mathrm{~m}$ to $5 \mathrm{~m}$ ) and

246 deeper levels (salinity average from $5 \mathrm{~m}$ to $10 \mathrm{~m})$ named "stratified" cases $\left(\overline{S_{\text {lnsıtu }[0 \mathrm{~m}: 5 \mathrm{~m}]}}-\right.$ $247 \overline{S_{\text {lnsitu }[5 \mathrm{~m}: 10 \mathrm{~m}]}}<-0.1 \mathrm{pss}$ ) and cases with a difference higher than -0.1 pss between shallower 248 (salinity average from $1 \mathrm{~m}$ to $5 \mathrm{~m})$ named "no-stratified" cases $\left(\overline{S_{\text {lnsitu }[0 \mathrm{~m}: 5 \mathrm{~m}]}}-\right.$ $249 \overline{S_{\text {lnsitu }[5 m: 10 m]}}>-0.1$ pss). The -0.1 pss threshold is chosen arbitrary in a context of SSS 250 validation. For "stratified cases", we observe a continuously increasing difference between $251 \mathrm{~S}_{\text {insitu }}$ and $\mathrm{SSS}_{\mathrm{S} M O S}$ with depth. In the "no-stratified" cases, as expected the difference is stable 252 as a function of depth, but a slight difference remains between $1 \mathrm{~m}$ and $2 \mathrm{~m}$ depth (Figure $2 \mathrm{~A}$ ). 253 Stratified cases are mainly recorded over shelf seas and in river plumes areas (Figure 2B). Cases 254 without stratification are mainly recorded in the North Atlantic and Barents Sea. Considering 2553228 CTD profiles: $81 \%$ are considered as not stratified whereas $19 \%$ are considered as 256 stratified (Figure 2C). Comparison of SSS $\mathrm{Smos}_{\text {with }} \mathrm{S}_{\mathrm{insitu}}$ at all depths show a higher scatter for 257 "no-stratified" cases than for stratified cases (Figure 2D). 


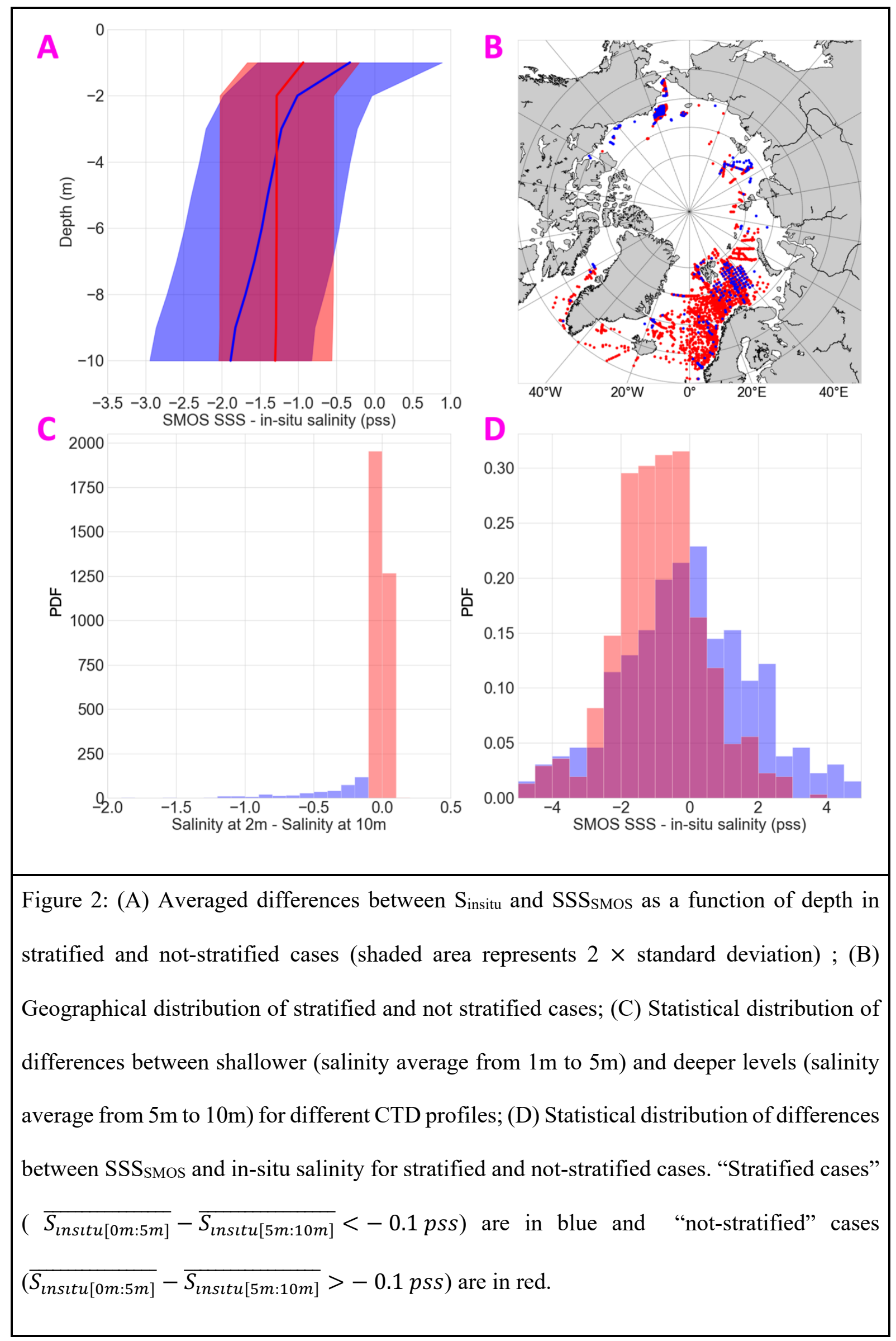


In the present study, we focus our investigations on five study areas representing two inflow 261 shelves with low stratification (Barents and Chukchi shelves), two more-stratified interior 262 shelves (Laptev and Beaufort shelves) and an Atlantic area. The details are as follows:

- Beaufort Sea: between $155^{\circ} \mathrm{W}$ and $130^{\circ} \mathrm{W}$ and between $68^{\circ} \mathrm{N}$ and $84^{\circ} \mathrm{N}$; the Beaufort Sea is characterized by the presence of the Beaufort gyre and a river plume from the Mackenzie river; the collocation dataset records the lower salinity values in the Beaufort 4 compare CTD measurements with $\mathrm{SSS}_{\mathrm{SMOS}}$ for each study area. In the salty regions (Barents

280 Sea and Atlantic area, Figure 3), the depth of in-situ measurements does not seem to influence strongly the relationship between $\mathrm{S}_{\mathrm{insitu}}$ and $\mathrm{SSS}_{\mathrm{SMOS}}$. These areas demonstrate very stable mean 
In fresher regions (Figure 5), in the Beaufort and Laptev Sea (figures 4A, B and 4E, F), 284 where the runoff of the Mackenzie and the Lena river are observed, important differences

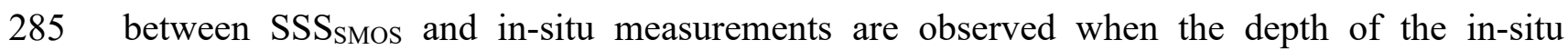
286 measurement increases. In the Laptev Sea, it is even stronger when the surface salinity is lower, 287 indicating a stronger stratification. In the Chukchi Sea (Figure 4C, D), the stratification effect 288 is less pronounced than in the Beaufort and the Laptev Seas. Figures 3 and 4 clearly show that, 289 as expected, stratification increases when the observed surface salinity decreases. In the 290 Beaufort Sea, the average difference between $1 \mathrm{~m}$ and $10 \mathrm{~m}$ depth is -1.84 pss (Figure 4B). In 291 the Laptev Sea, average difference between $2 \mathrm{~m}$ and $10 \mathrm{~m}$ depth is -1.47 pss (Figure 4F). The 292 STDD between SSS $_{\text {SMos }}$ and $\mathrm{S}_{\text {insitu }}$ is also strongly affected by the stratification: in the Beaufort 293 Sea STDD increase from $1.47 \mathrm{pss}(1 \mathrm{~m}$ depth) to $2.29 \mathrm{pss}(10 \mathrm{~m}$ depth) and from $1.83 \mathrm{pss}(2 \mathrm{~m}$ 294 depth) to 2.12 pss (10 m depth) in the Laptev Sea. 


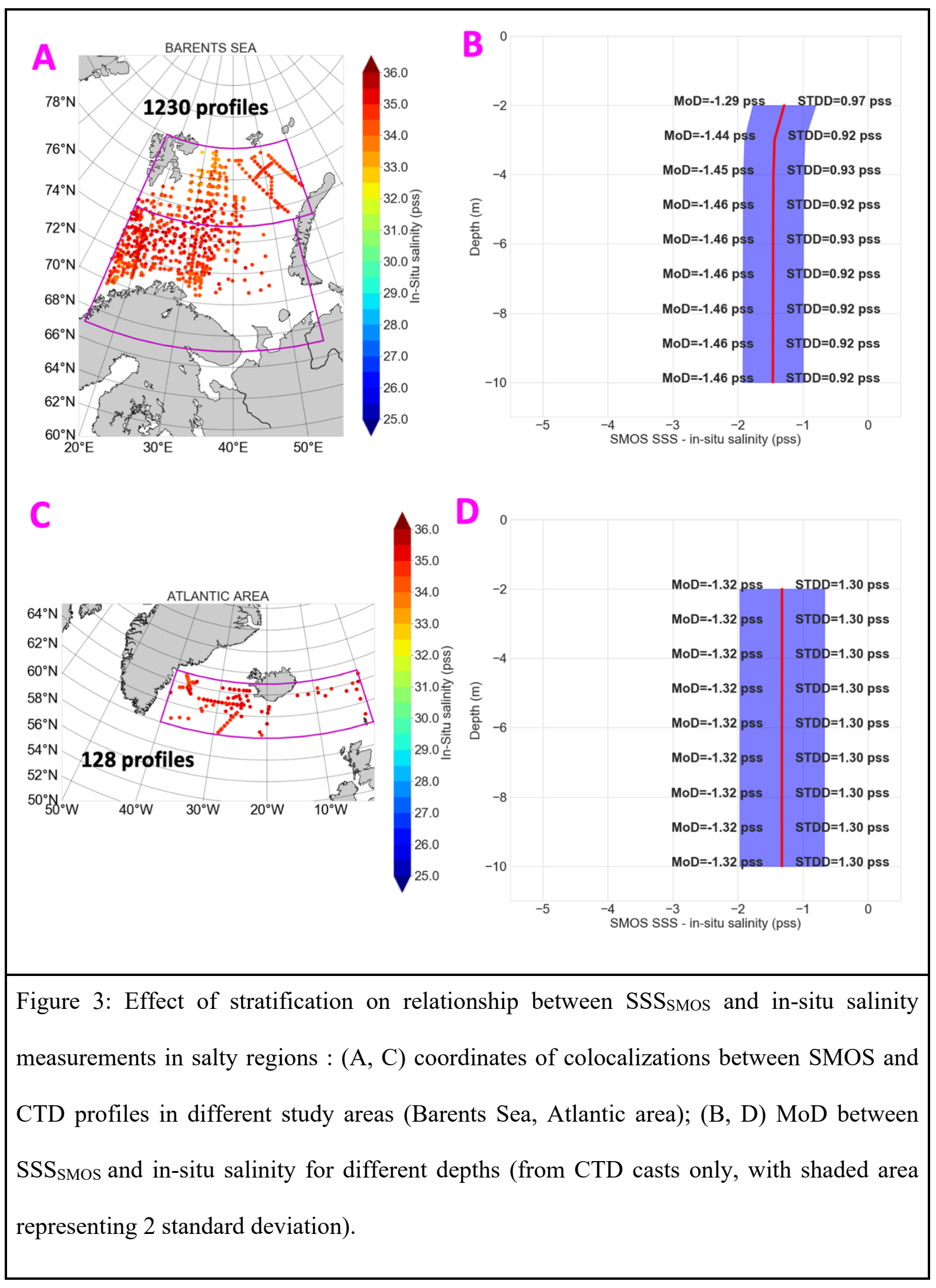




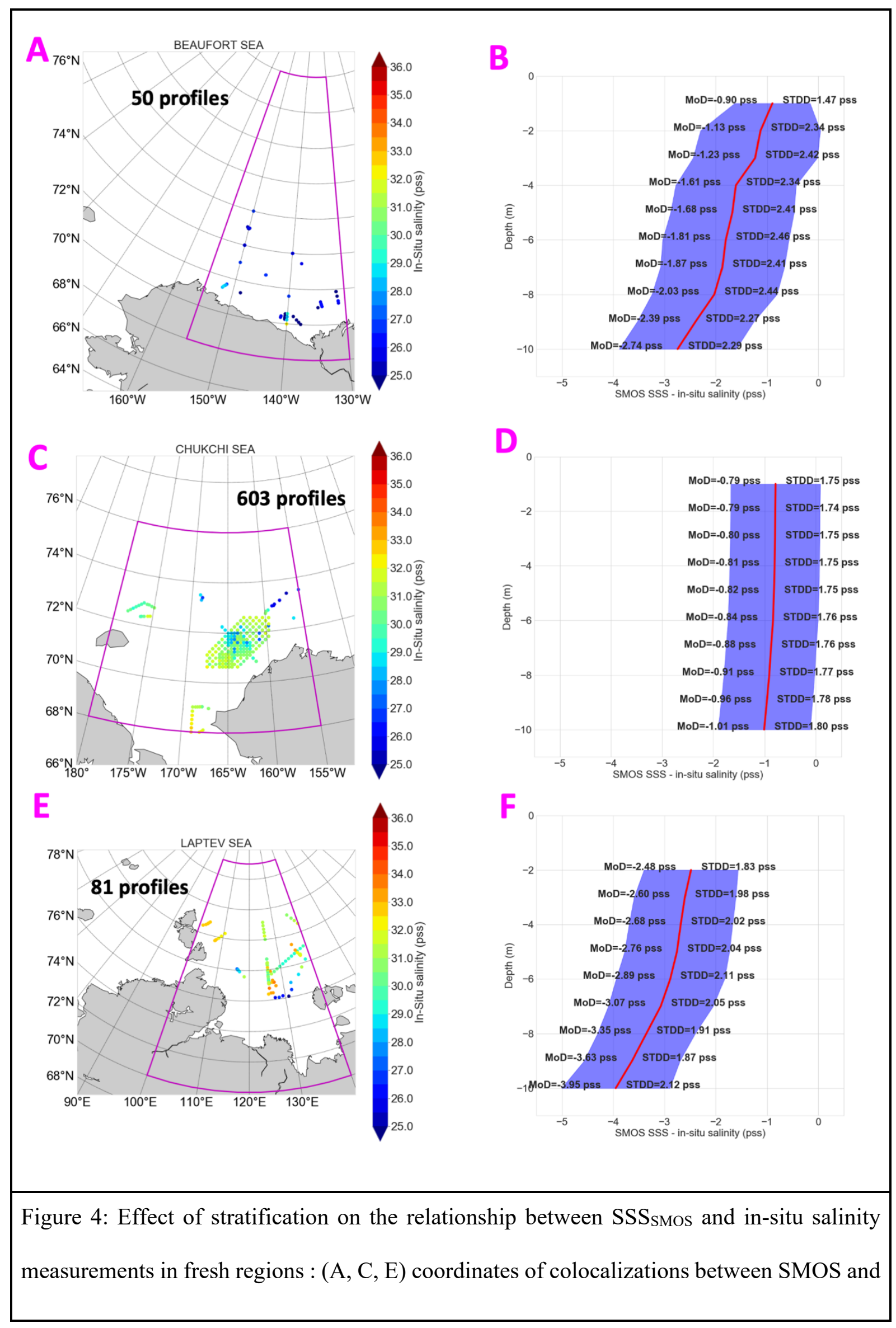


CTD profiles in the different study areas (Beaufort Sea, Chukchi Sea, Laptev Sea); (B, D, F) MoD between $\mathrm{SSS}_{\mathrm{S} M O S}$ and in-situ salinity for different depths (from CTD casts only, with shaded area representing 2 standard deviation).

3.3. Selection of in-situ measurements for absolute SSS calibration and validation

The selection of $\mathrm{S}_{\text {insitu }}$ for comparison and validation with satellite SSS is a compromise between the need for a set of in-situ measurements representative of the whole Artic Ocean and the need for in-situ measurements representative of SMOS estimates $(1 \mathrm{~cm} \mathrm{depth})$.

We select $S_{\text {insitu }}$ according to depth in order to avoid as much as possible the effect of vertical

301 stratification. However, in situ measurements between $1 \mathrm{~m}$ and $5 \mathrm{~m}$ depth cover much broader 302 regions and in particular fresh areas not sampled by in situ measurements between $1 \mathrm{~m}$ and $3 \mathrm{~m}$ 303 depth (Appendix-C). Hence, for the validation purpose (section 5.2), the maximum depth of $304 S_{\text {insitu }}$ is set at $5 \mathrm{~m}$.

305 On the other hand, the absolute calibration (constant bias removal) of SMOS SSS is 306 performed in a salty area less prone to stratification effects, the Barents Sea, where we only 307 consider the uppermost $\mathrm{S}_{\text {insitu. }}$

4. Novel corrections and filtering: methodology

A main contamination of satellite SSS at high latitude comes from the presence of sea ice

312 (Tang et al. 2018) which emissivity is much higher than the one of the surface ocean due to a 313 much lower dielectric constant. Our filtering procedure will take advantage of L3 Acard.

314 Acard may be retrieved directly from SMOS TB and a prior SST, considering only 315 emissivity and Fresnel equations, independently from the dielectric constant model (Table 1). 316 It is named Acard ${ }_{\mathrm{SmOS}}$ below. It is also possible to compute Acard (Acard $\mathrm{KS}_{\mathrm{K}}$ ) from a theoretical 
317 dielectric constant model using equation [A2] (Appendix-A). We use the KS dielectric constant 318 model also used to retrieve SSS in the L2 OS processor. The difference between Acardsmos and

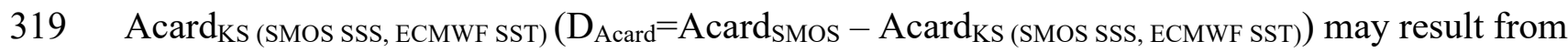
320 either:

- an imperfect representation of the dielectric properties of the observed surface by the KS model, or,

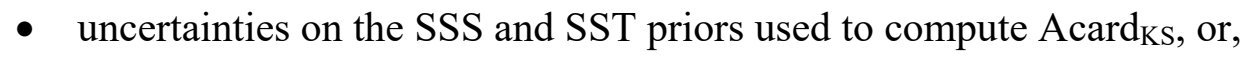

- residual errors in the correction of atmospheric, solar and sky glint, or sea surface roughness used to estimate the flat sea surface radio-brightness contrast, or,

- And/or from corrupted SMOS TB (RFI, image reconstruction errors, etc.) used to retrieved Acardsmos.

In the following, we address uncertainties coming from the first two items. We compute

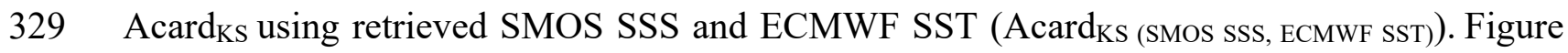
330 5A illustrates the relationship between SSS and Acard for different SST. Academic simulations

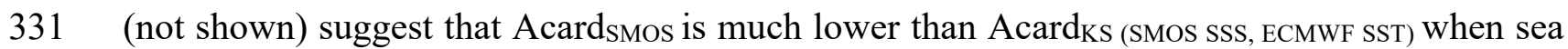
332 ice is present within a SMOS pixel. 

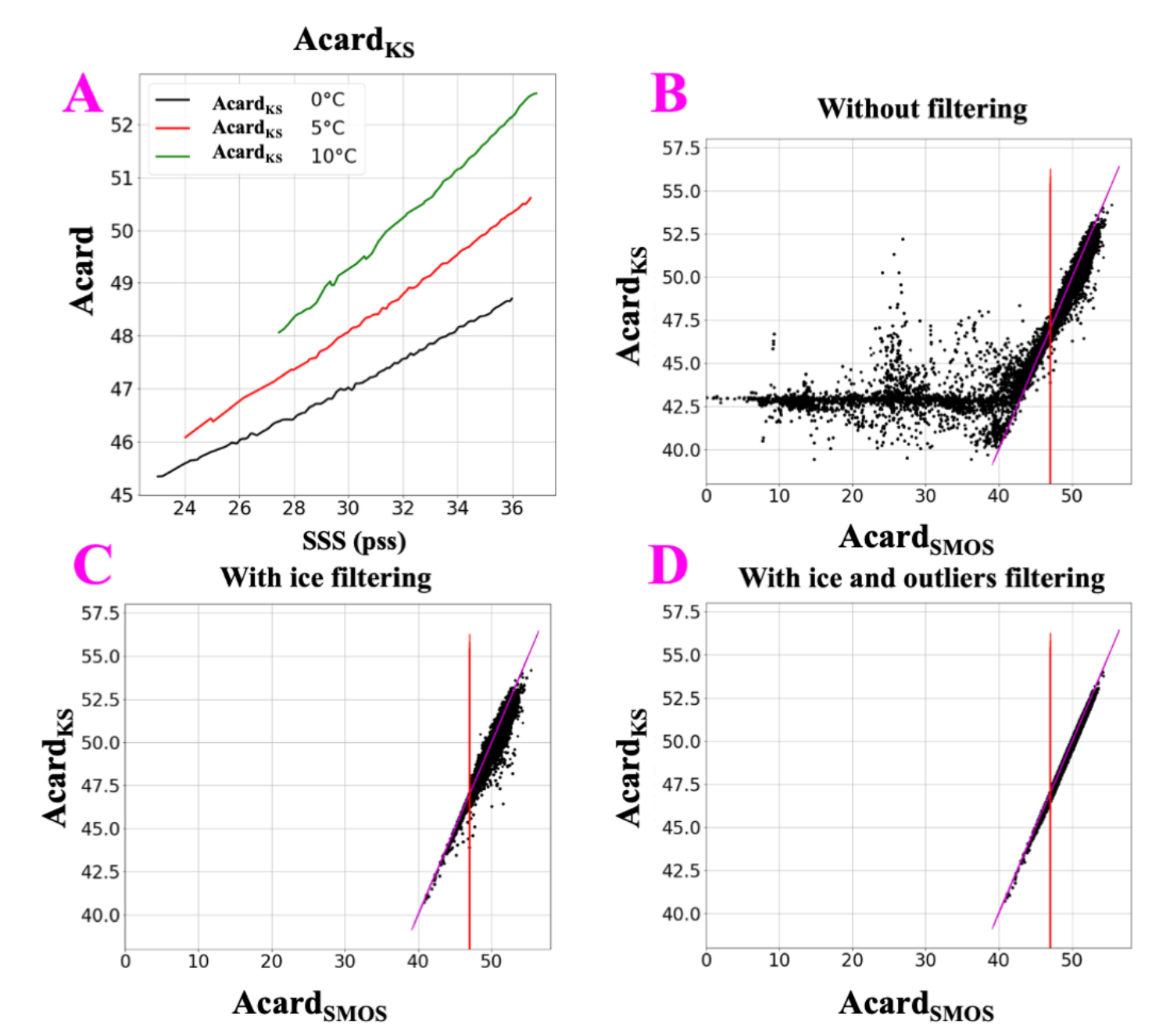

Figure 5: (A) Relationship between Acard and SSS at various SST considering KS model;

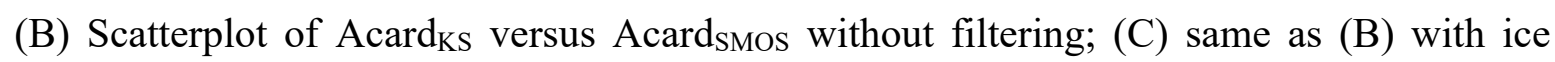
filtering (first step); (D) same as (B) with ice filtering and outliers filtering (second step); (red) Acardsmos $_{\mathrm{S}} 47$ threshold; (magenta) line corresponding to Acard $_{\mathrm{KS}}=$ Acard $_{\mathrm{SMOS}}$.

334 Based on these considerations, we developed a two-step filtering methodology. As

335 illustrated in Figure 5B which represents AcardsMOs as a function of Acard KS $_{\text {(SMOS SSS, ECMWF }}$

336 SST) without applying any filtering: two main regimes are observed. The first regime (points on

337 the diagonal, above 40, Figure 5B), corresponds to the expected behavior between Acardsmos

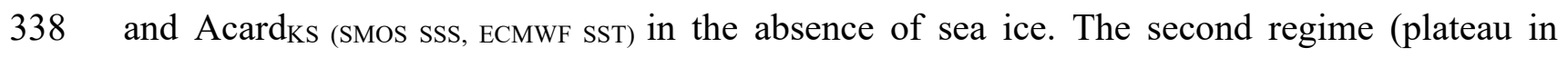


Acard $_{\mathrm{KS}}$, below 40, Figure 5B) with large differences between Acardsmos and Acard KS $_{\text {(SMOS SSS, }}$

340 ECMWF SST) is due to pixel partially covered by sea ice and/or an inappropriate use of KS in order

341 to compute Acard in these cases (KS model is designed for sea ice free ocean conditions). We

342 note that the probability to observe the second regime case strongly increases with an Acard

343 value lower than 47. In a first step, when Acard is less than 47, we apply a very restrictive filter

344 by removing all pixels with a $\mathrm{D}_{\text {Acard }}$ value lower than -0.1 (Figure $5 \mathrm{C}$ ). In a second step, we 345 filter out $\mathrm{D}_{\text {Acard }}$ values lower than -0.21 and larger than 0.52 , that correspond respectively to the 3460.05 and 0.95 percentiles of $\mathrm{D}_{\text {Acard }}$ distribution after ice filtering (Figure 5D).

347 4.2. Absolute calibration of SSS

348 Considering differences with respect to upper $S_{\text {insitu }}$ in the Barents Sea (Figure 3B), we add 3491.29 pss to SMOS SSS for removing the SMOS SSS global bias.

$350 \quad$ 4.3. Correction related to uncertainty on the dielectric constant model

351 Flaws in the dielectric constant model may lead to errors on both the retrieved SSSSMOs and

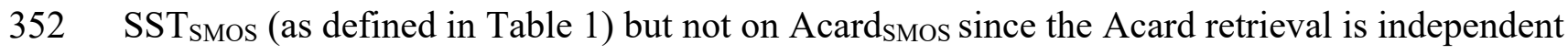
353 of any dielectric constant model. As a first approximation, we assume that errors in the dielectric 354 model only induce biases in the retrieved $\mathrm{SSS}_{\mathrm{SMOS}}$ and not on retrieved SST. We compare 355 Acard $_{\text {SMOS }}$ with Acard ${ }_{\mathrm{KS}}$ computed with parameters available in the SMOS User Data Product, 356 i.e. $\mathrm{SSS}_{\mathrm{SMOS}}$ and $\mathrm{SST}_{\mathrm{ECMWF}}$. A first correction on $\mathrm{SSS}_{\mathrm{SMOS}}$ can then be determined using the following relationship that also consider absolute calibration (section 4.2.):

$$
\mathrm{SSS}_{\mathrm{SMOS} \mathrm{A}}=\mathrm{SSS}_{\mathrm{SMOS}}+\frac{\left(\text { Acard }_{\mathrm{KS}}-\text { Acard }_{\mathrm{SMOS}}\right)}{\lambda\left(\mathrm{SST}_{\mathrm{ECMWF}}, \mathrm{SSS}_{\mathrm{SMOS}}\right)}+1.29
$$

where $\lambda(\mathrm{SST}, \mathrm{SSS})=\frac{\partial \operatorname{Acard}_{\mathrm{KS}}(\mathrm{SST}, \mathrm{SSS})}{\partial \mathrm{SSS}}$.

Figure 8 shows differences between Acardsmos and Acard $_{\mathrm{Ks}}$. Acard SMOS $_{\mathrm{S}}$ is plotted as a

361 function of SST and $\mathrm{SSS}_{\mathrm{SMOS} \text { A }}-1.29$ in order to be comparable to Acard $\mathrm{KS}_{\mathrm{K}}$ computed with 362 SSS $_{\text {SMOS }}$ (Figure 6A). Differences between Acard SMOS $_{\text {and }}$ Acard $\mathrm{KS}_{\mathrm{KS}}$ are larger for low SSS and low SST (Figure 6C). This correction integrates different biases that can not be disentangled in 
364 this study: 1) SSS bias coming from the KS model; 2) SSS bias due to a potential difference 365 between SST retrieved with SMOS and SSTECMwF.
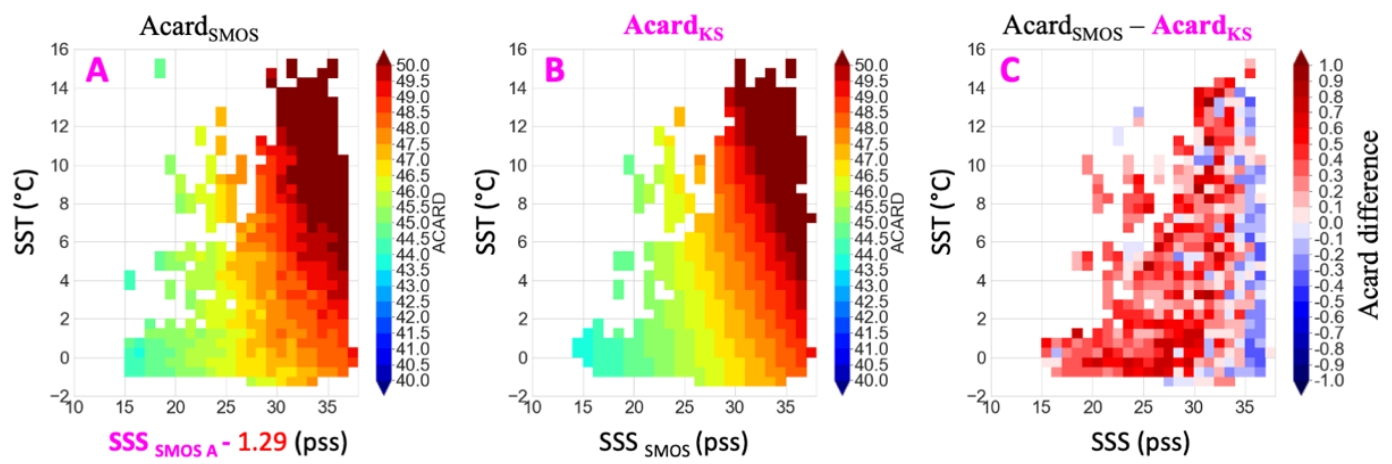

Figure 6: (A) Acard $\mathrm{SMOS}_{\mathrm{S}}$ as a function of $\mathrm{SST}_{\mathrm{ECMWF}}$ and $\mathrm{SSS}_{\mathrm{SMOS}} \mathrm{A}-1.29$ Acard ${ }_{\mathrm{KS} \text { (SMOS }}$

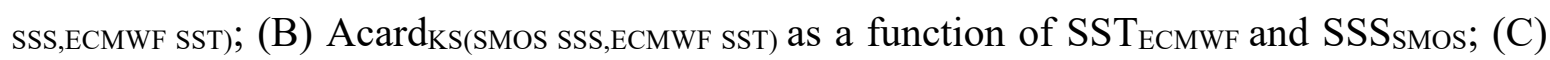
Difference between Acardsmos and Acard ${ }_{\mathrm{KS}}$. SMOS retrieved variables are in black, computed variables are in magenta.

We observe that in some regions such as the Lena river plume in the Laptev Sea, $\mathrm{SST}_{\mathrm{ECMWF}}$ is nevertheless underestimated with respect to upper in-situ temperature, $\mathrm{T}_{\text {insitu. }}$. As shown in Appendix-D (Figure D1), stronger SST gradient are observed in REMSS SST product compared with OSTIA SST used in ECMWF. Based on the KS model, it is possible to compute a second correction of the retrieved SSS considering sensitivity to SST and selecting another

373 SST product as reference (here chosen to be REMSS SST):

$$
\mathrm{SSS}_{\mathrm{SMOS} \mathrm{A}+\mathrm{T}}=\mathrm{SSS}_{\mathrm{SMOS} \mathrm{A}}+\frac{\gamma\left(\mathrm{SST}_{\mathrm{ECMWF}}, \mathrm{SSS}_{\mathrm{SMOS}}\right)}{\beta\left(\mathrm{SST}_{\mathrm{ECMWF}}, \mathrm{SSS}_{\mathrm{SMOS}}\right)}\left(\mathrm{SST}_{\mathrm{ECMWF}}-\mathrm{SST}_{\mathrm{REMSS}}\right)
$$

375 where $\beta(\mathrm{SST}, \mathrm{SSS})=\frac{\partial \mathrm{TB}(\mathrm{SST}, \mathrm{SSS})}{\partial \mathrm{SSS}}$ and $\gamma(\mathrm{SST}, \mathrm{SSS})=\frac{\partial \mathrm{TB}(\mathrm{SST}, \mathrm{SSS})}{\partial \mathrm{SST}}$. 
To assess the efficiency of the Acard filtering for sea ice we used SIC data from TOPAZ

380 and we analyze a case study in the Laptev Sea. As illustrated on Figure 7, without the Acard

381 filtering, low SSS values are observed in the northernmost areas in the vicinity of sea ice edges

382 because of a too permissive filtering of ice in the ESA L2 processor. At these locations, negative

$383 \mathrm{D}_{\text {Acard }}$ and positive SIC from TOPAZ are observed.

A
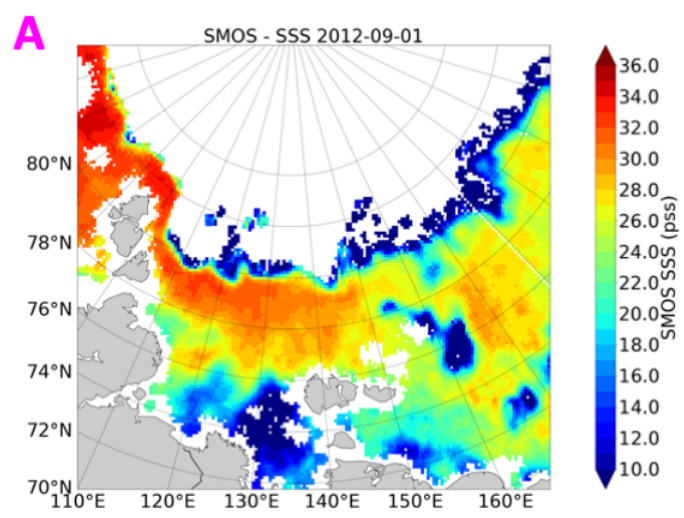

C

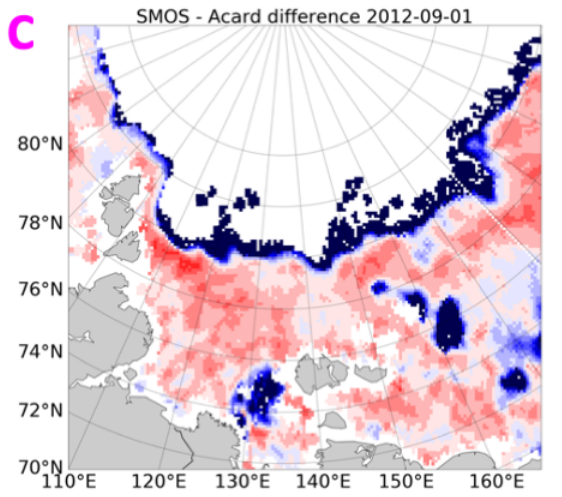

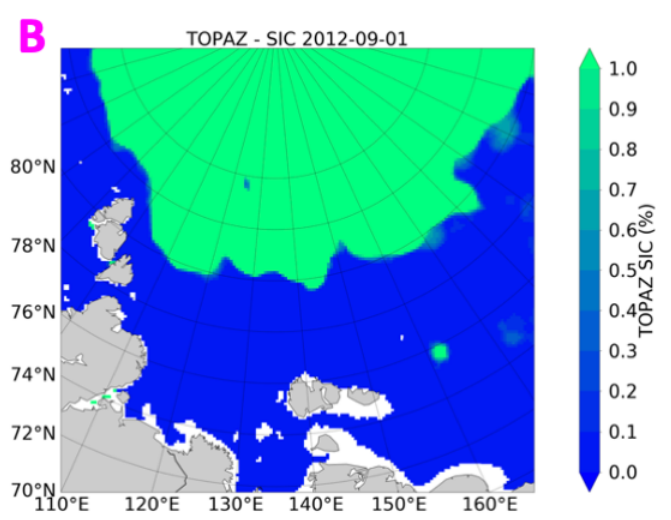

D

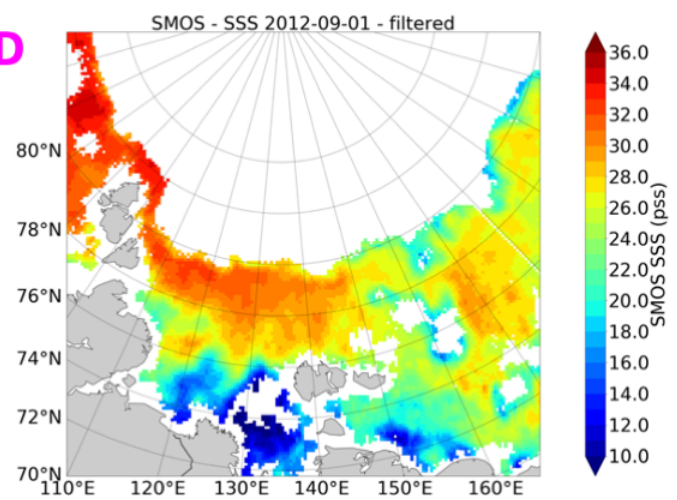

Figure 7: L3 post-processing flagging for the study case of 2012-09-01: (A) SMOS SSS preprocessed L3 estimates; (B) TOPAZ reanalysis SIC; (C) differences between Acardsmos and

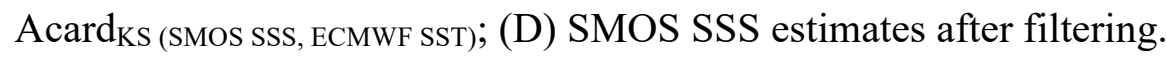

Over the whole Arctic Ocean and period investigated (Figure 8), Acard ice filtering removes all pixels with SIC larger than $2.5 \%$ and most pixels with SIC in the range of $0 \%$ - 
2.5\%. MoD and STDD with respect to in-situ SSS significantly decrease after filtering and do not show a dependency to TOPAZ SIC anymore suggesting that the remaining SMOS pixels

389 are not significantly polluted by sea ice. These results demonstrate the efficiency of Acard ice

390 filtering over using an external SIC product. Hereafter, we refer to SSS $\mathrm{SmOS}$ as the SMOS SSS

391 obtained after the above described processing. $\mathrm{SSS}_{\mathrm{S} M O S}$ considered in the following are

392 therefore sea ice filtered.
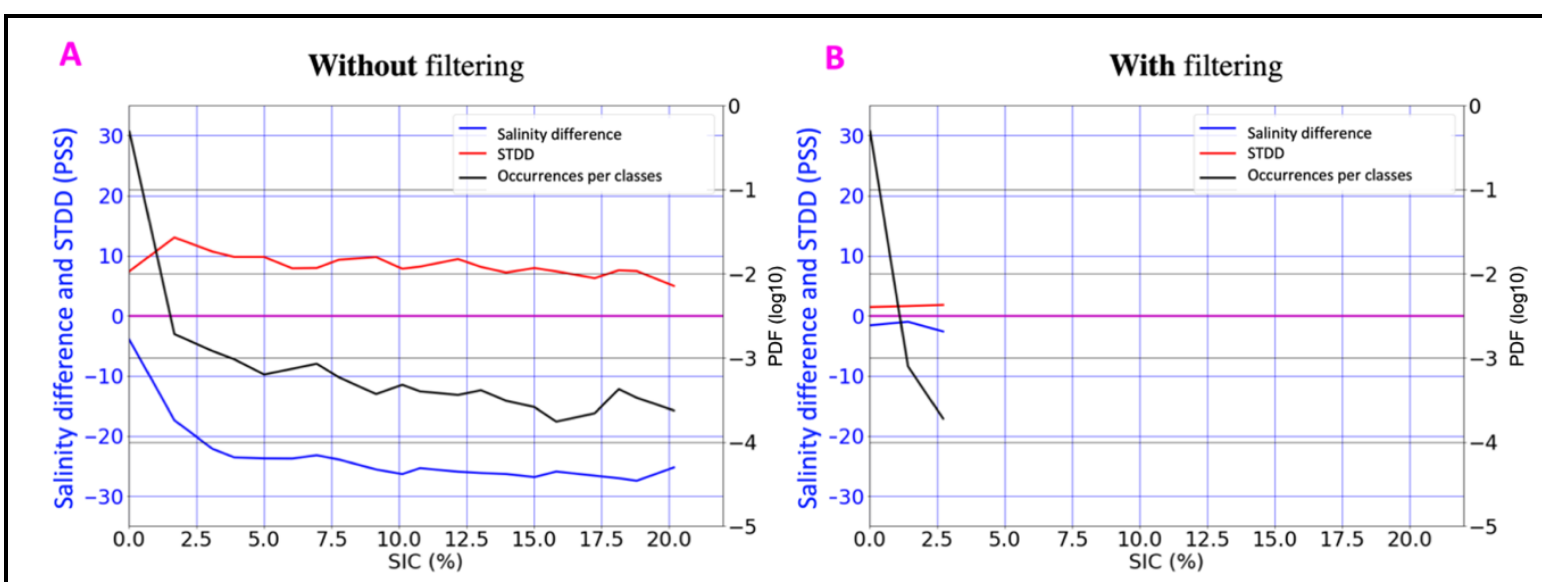

Figure 8: Mean difference and STDD between SMOS SSS and in-situ salinity and PDF of collocations per bin (bin size: 1\%) of TOPAZ SIC; (A) without filtering; (B) with filtering. 


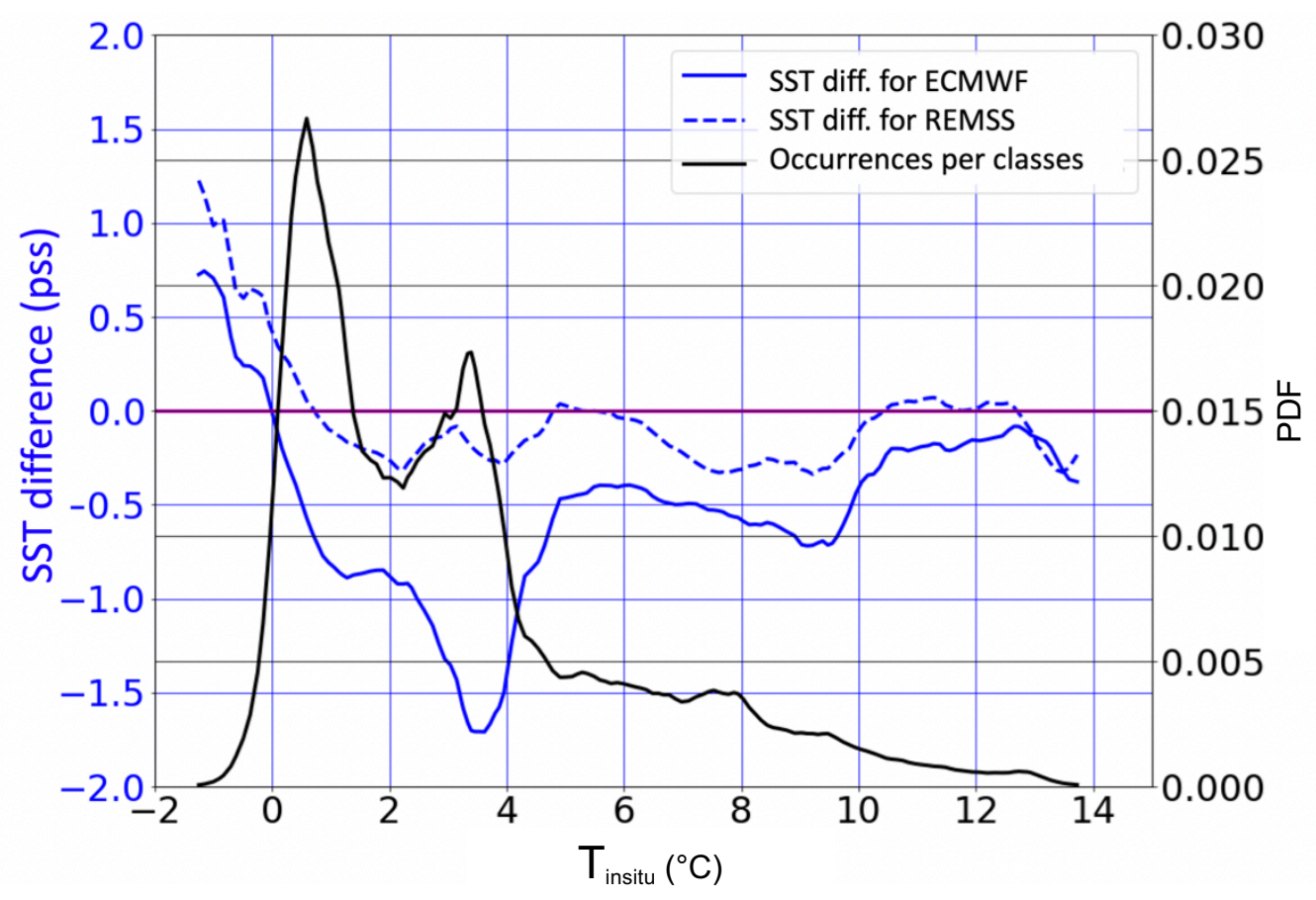

Figure 9: Difference of $\mathrm{SST}_{\mathrm{ECMWF}}-\mathrm{T}_{\text {insitu }}$ (blue line) and $\mathrm{SST}_{\mathrm{REMSS}}-\mathrm{T}_{\text {insitu }}$ (blue dashed line) as a function of $\mathrm{T}_{\text {insitu. }}$. Distribution of $\mathrm{T}_{\text {insitu }}$ (black line); (bin size: $1{ }^{\circ} \mathrm{C}-$ sliding window).

The main motivation for the temperature-dependent correction is found in the distribution of SST. As shown in Figure 9, $\mathrm{SST}_{\text {REMSS }}$ are closer to in-situ SST than $\mathrm{SST}_{\text {ECMwF. }}$

397 Depending on the Arctic Ocean regions considered, two modes are generally present in both 398 the distribution of SST REMSS and in-situ SST (Figure 10 and 11) but the mode corresponding to 399 higher temperatures is almost absent in the $\mathrm{SST}_{\mathrm{ECMWF}}$ distribution.

In order to make a realistic comparison of the statistical distributions of SMOS and in 401 situ SSS, in each area we add noise to $\mathrm{S}_{\text {insitu }}$ to mimic SMOS noise, considering a Gaussian 402 noise being derived from the theoretical uncertainty of the collocated SMOS L3 SSS. The positive effect of the correction is clear in Chukchi and Laptev Seas. For these two regions, $\mathrm{SST}_{\mathrm{ECMWF}}$ distribution clearly underestimates the warmest SST mode (Figures 10H, I) 405 in comparison with REMSS, or, $\mathrm{T}_{\text {insitu. }}$ This results into a distribution of SMOS SSS without

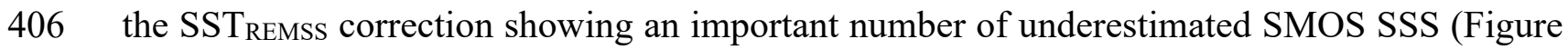
407 10B, C). This correction results in a distribution of SMOS SSS closer to the $\mathrm{S}_{\text {insitu }}$ distribution 
408 (Figures 10E, F), thus the STDD and MoD decrease and the correlation coefficient (r) increases

409 (Table 2) for the Chukchi Sea and the Laptev Sea.

410 To a lower extent, the same kind of difference is observed in the Beaufort Sea (Figures

411 10A, D, G). In the Barents Sea, the $\mathrm{SST}_{\mathrm{ECMwF}}$ distribution is closer to that of $\mathrm{T}_{\text {insitu }}$ and

$412 \mathrm{SST}_{\text {REMSS }}$ than for the other study areas and our correction only brings a very small 413 improvement (Figures 11A, D, G and STDD in Table 1). Finally, the Atlantic area presents a 414 degradation of SSS after Acard difference and SST corrections (Figures 11B, E, H and STDD 415 in Table 2). This is mainly due to the Acard correction (Appendix-E). Indeed, this correction 416 assumes that error in the SSS estimation comes from errors in dielectric constant model and/or 417 from erroneous prior SST. In the Atlantic area, RFI likely disturb TB such that their angular 418 variation cannot be described with a Fresnel model, and therefore our correction is not 419 appropriate.

420 Considering the whole Arctic Ocean (Figures 11C, F, I), the distribution of the corrected 421 SMOS SSS fits better $S_{\text {insitu. }}$ After correction, the STDD and MoD improve from 1.46 pss to 4221.28 pss and from -1.54 pss to -0.27 pss, respectively; $r$ increases from 0.92 to 0.94 (Table 2). 


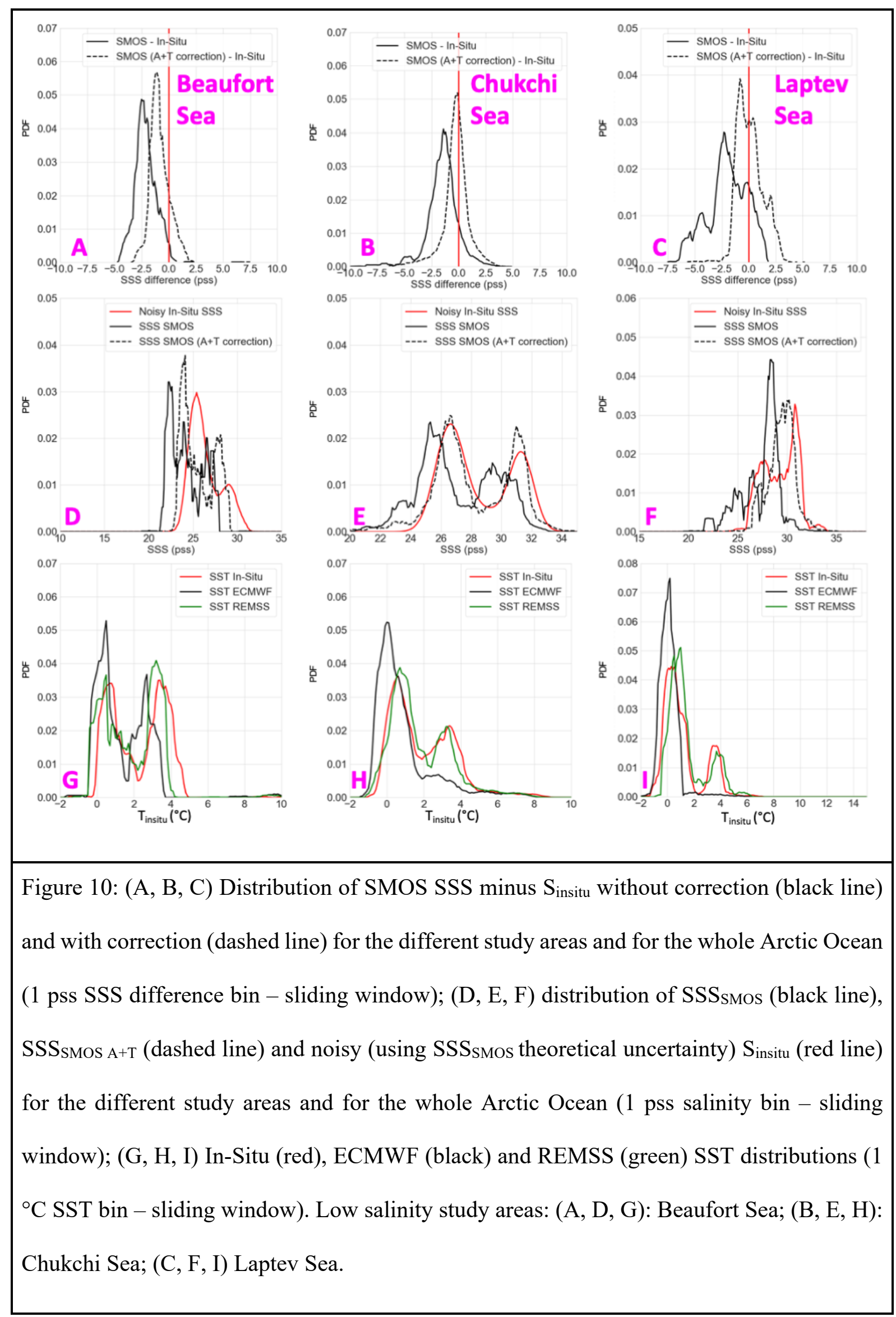




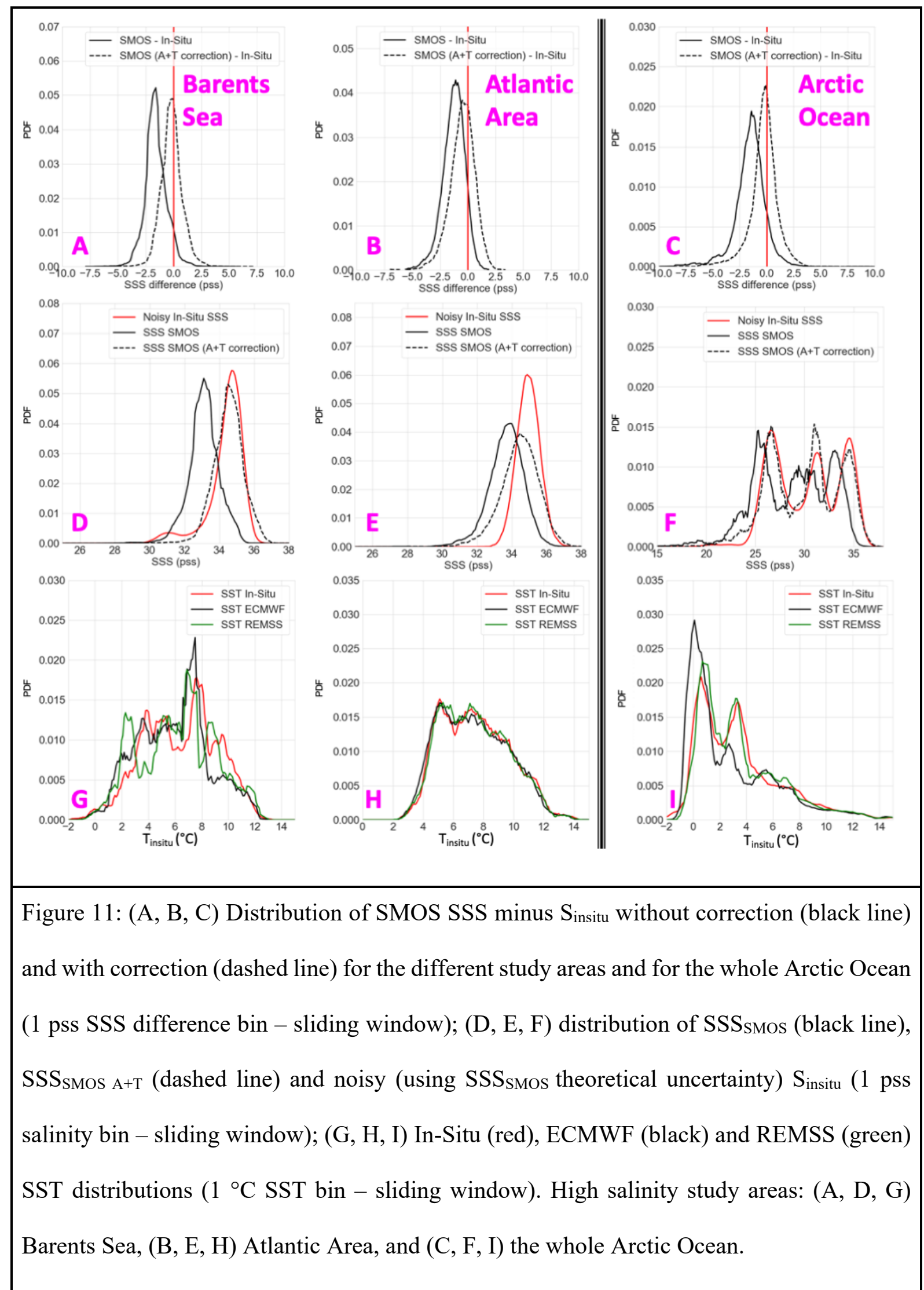

424 Over the whole Arctic Ocean, the difference between SST REMSS and $\mathrm{T}_{\text {insitu }}$ is less than the

425 difference observed between $\mathrm{SST}_{\mathrm{ECMWF}}$ and $\mathrm{T}_{\text {insitu. }}$. The difference $\mathrm{SST}_{\mathrm{ECMWF}}-\mathrm{T}_{\text {insitu }}$ exceeds - 
$4261^{\circ} \mathrm{C}$ for $\mathrm{T}_{\text {insitu }}$ between $3{ }^{\circ} \mathrm{C}$ and $4{ }^{\circ} \mathrm{C}$, temperatures that are often present in the Arctic Ocean

427 (figures 9 and 11I). In this SST range, the correction is efficient to reduce the satellite SSS 428 differences with respect to $\mathrm{T}_{\text {insitu. }}$. The overestimation of SST observed with both ECMWF and 429 REMSS products for SST lower than $0^{\circ} \mathrm{C}$ (Figure 9) should lead to an overestimation of SSS 430 (Figure 12). However, an underestimation of SSS is observed for the coldest surface 431 temperatures without any link with SST difference, likely due to some remaining very low sea 432 ice concentration or very near surface freshening close to sea ice unidentified with in-situ 433 measurements.

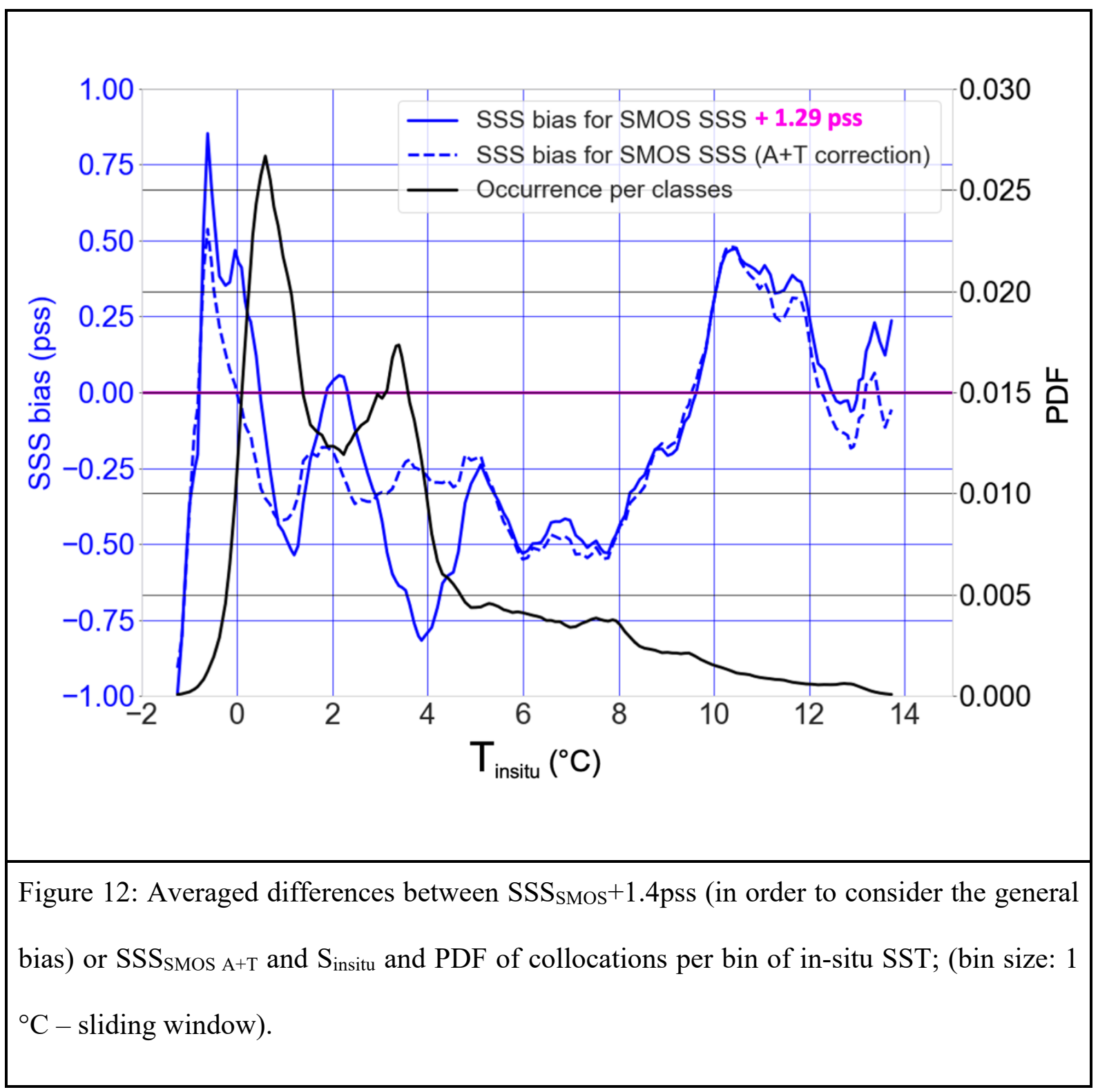


435 Table 2: Comparisons between SMOS SSS, without and with correction, TOPAZ SSS and $436 \quad \mathrm{~S}_{\text {insitu }}$ for the different study areas ( $\mathrm{N}$ is the number of collocations).

\begin{tabular}{|c|c|c|c|c|}
\hline Cases study & Statistic indicator & $\mathrm{SSS}_{\mathrm{SMOS}}$ & $\mathrm{SSS}_{\mathrm{SMOS} \mathrm{A}+\mathrm{T}}$ & $\mathrm{SSS}_{\text {TOPAZ }}$ \\
\hline \multirow[t]{4}{*}{ Beaufort Sea } & MoD (pss) & -2.12 & -0.83 & 3.67 \\
\hline & STDD (pss) & 0.96 & 0.88 & 1.18 \\
\hline & $\mathrm{r}$ & 0.86 & 0.88 & 0.86 \\
\hline & $\mathrm{N}$ & 3912 & 3912 & 3912 \\
\hline \multirow[t]{4}{*}{ Chukchi Sea } & MoD (pss) & -1.50 & -1.28 & 1.97 \\
\hline & STDD (pss) & 1.47 & 1.23 & 1.78 \\
\hline & $\mathrm{r}$ & 0.84 & 0.88 & 0.86 \\
\hline & $\mathrm{N}$ & 90721 & 90721 & 90721 \\
\hline \multirow[t]{4}{*}{ Laptev Sea } & MoD (pss) & -1.97 & 0.11 & 1.51 \\
\hline & STDD (pss) & 1.82 & 1.17 & 1.89 \\
\hline & $\mathrm{r}$ & 0.53 & 0.75 & 0.04 \\
\hline & $\mathrm{N}$ & 4048 & 4048 & 4048 \\
\hline \multirow[t]{3}{*}{ Barents Sea } & MoD (pss) & -1.59 & -0.17 & -0.19 \\
\hline & STDD (pss) & 0.96 & 0.94 & 0.50 \\
\hline & $\mathrm{r}$ & -0.03 & -0.04 & 0.19 \\
\hline
\end{tabular}




\begin{tabular}{|l|c|c|c|c|}
\hline & $\mathrm{N}$ & 10879 & 10879 & 10879 \\
\hline Atlantic Area & MoD (pss) & -1.29 & -0.51 & 0.01 \\
\hline & STDD (pss) & 1.02 & 1.13 & 0.10 \\
\hline & $\mathrm{r}$ & 0.01 & -0.05 & 0.70 \\
\hline Arctic Ocean & MoD (pss) & -1.54 & -0.27 & 1.25 \\
\hline & STDD (pss) & 1.46 & 1.28 & 1.86 \\
\hline & $\mathrm{r}$ & 0.92 & 0.94 & 0.89 \\
\hline & $\mathrm{N}$ & 156986 & 156986 & 156986 \\
\hline & & & & \\
\hline & & & & \\
\hline
\end{tabular}

438 6. Comparisons between SMOS SSS and TOPAZ SSS

$439 \quad 6.1$. Weekly variability

440 To assess the capability of the corrected SMOS SSS products to reproduce the short

441 scale SSS variability in the Arctic relative to an ocean circulation model, we compare hereafter

442 SSS $_{\mathrm{SmOS}}$ A+T and SSS $\mathrm{SOPAZ}_{\mathrm{T}}$ (Table 3 ) to a reference salinity provided by underway TSG tracks 443 acquired in three different seas: Greenland Sea (case study 1), Laptev Sea (case study 2) and 444 Chukchi Sea (case study 3). For the case study in the Greenland Sea, the vessel is arriving from 445 an area covered by sea ice. It first crosses an area of low salinity before an area with SSS $\sim 35$ 446 pss. Both $\mathrm{SSS}_{\mathrm{SMOS} \mathrm{A}}+\mathrm{T}$ and $\mathrm{SSS}_{\mathrm{TOPAZ}}$ do not reach the lower values recorded by the TSG (Figure 447 13A, B). Only one $\mathrm{SSS}_{\mathrm{SMOS} \text { А+T }}$ pixel reaches a value lower than $26 \mathrm{pss}$, but an effect of ice may 448 not be excluded even if the SIC from TOPAZ indicates no ice. SSS $S_{\mathrm{SMOS} A+\mathrm{T}}$ exhibits better 449 STDD and MoD than SSSTopaz with respect to the TSG. For the study case in the Laptev Sea 
450 (Figure 13C and 13D), $\mathrm{SSS}_{\mathrm{SmOS} \text { A+T }}$ show a positive bias (larger than $\mathrm{SSS}_{\mathrm{TOPAZ}}$ ) for higher SSS 451 values recorded by the TSG contrary to $\mathrm{SSS}_{\mathrm{TOPAZ}}$ which fits well with these salinities. However, 452 the large freshening (more than 10 pss) observed by the vessel crossing the Lena river plume is 453 very well represented by $\mathrm{SSS}_{\mathrm{SMOS} \mathrm{A}}$ +T contrary to $\mathrm{SSS}_{\mathrm{TOPAz}}$, which misses the location of the 454 river plume and its intensity. Nevertheless, $\mathrm{SSS}_{\mathrm{SMOS}} \mathrm{A}_{+\mathrm{T}}$ demonstrates in this case a higher

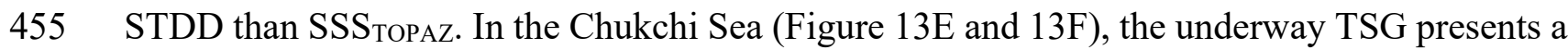
456 large variability also observed by $\operatorname{SSS}_{\mathrm{SMOS}} \mathrm{A}+\mathrm{T}$ but with some bias. This variability is not 457 recorded by SSSTOPAz. The STDD and bias with respect in situ data, are lower with SSS SMOS $458 \quad \mathrm{~A}+\mathrm{T}$ than with $\mathrm{SSS}_{\mathrm{TOPAz}}$ by $\sim 0.2$ and 0.3 , respectively. 

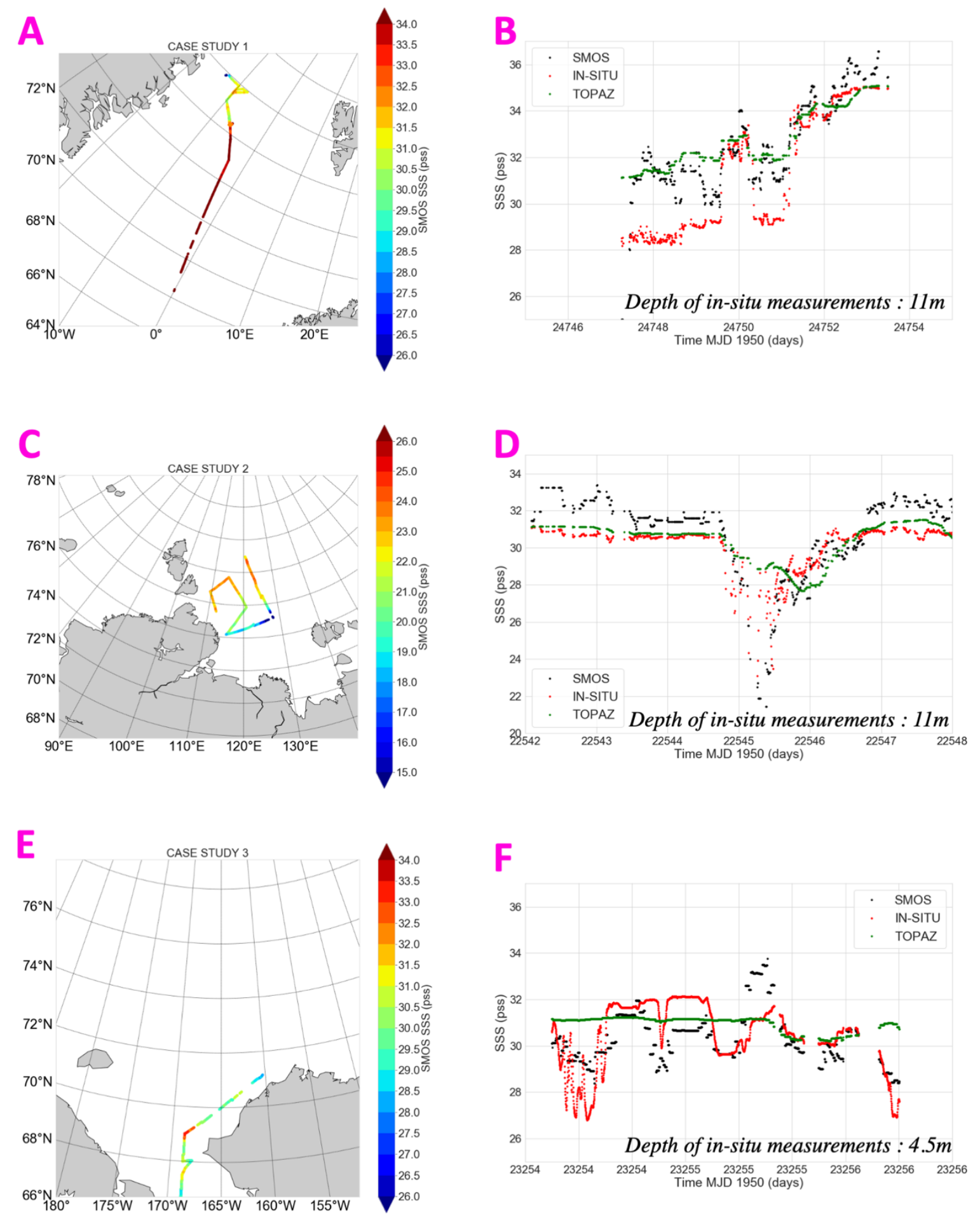

Figure 13: (A, C, E) SMOS SSS measurements collocated with underway TSG measurements; (B, D, F) Time series of SMOS SSS (black) and TOPAZ SSS (green) 
collocated with underway TSG salinity measurements (red). Case studies in the Greenland Sea (A, D, G), in the Laptev Sea (B, E, H) and Chukchi Sea (C, F, I).

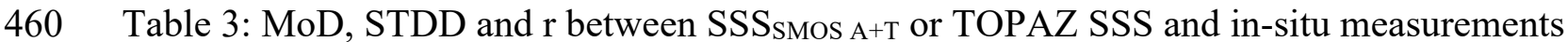

461 for the underway TSG case studies.

\begin{tabular}{|c|c|c|c|}
\hline Cases study & Statistic indicator & $\mathrm{SSS}_{\mathrm{SMOS}} \mathrm{A}+\mathrm{T}$ & $\mathrm{SSS}_{\text {TOPAZ }}$ \\
\hline \multirow[t]{3}{*}{ Case study 1} & MoD (pss) & 1.25 & 1.41 \\
\hline & STDD (pss) & 1.27 & 1.43 \\
\hline & $\mathrm{r}$ & 0.88 & 0.96 \\
\hline \multirow[t]{3}{*}{ Case study 2} & MoD (pss) & 0.59 & 0.25 \\
\hline & STDD (pss) & 1.37 & 0.98 \\
\hline & $\mathrm{r}$ & 0.84 & 0.69 \\
\hline \multirow[t]{3}{*}{ Case study 3} & MoD (pss) & -0.15 & 0.51 \\
\hline & STDD (pss) & 1.24 & 1.43 \\
\hline & $\mathrm{r}$ & 0.56 & 0.12 \\
\hline
\end{tabular}

In Figure 14, $\mathrm{SSS}_{\mathrm{SMOS}} \mathrm{A}+\mathrm{T}$ and $\mathrm{SSS}_{\mathrm{TOPAZ}}$ distributions are compared with $\mathrm{S}_{\text {insitu }}$

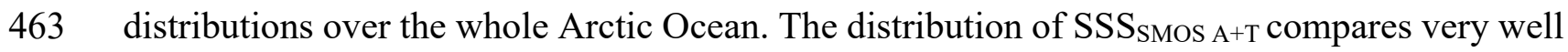

464 with the distribution of $S_{\text {insitu }}$ (Figure 14A). One mode of the $S_{\text {insitu }}$ distribution (lower SSS) is 465 totally absent in the $\mathrm{SSS}_{\mathrm{TOPAZ}}$ distribution. STDD (Table 2) is 1.28 pss for $\mathrm{SSS}_{\mathrm{SMOS} \mathrm{A}}+\mathrm{T}$ and 4661.86 pss for $\mathrm{SSS}_{\mathrm{TOPAZ}} \mathrm{r}$ reaches 0.94 with $\mathrm{SSS}_{\mathrm{SMOS}} \mathrm{A}+\mathrm{T}$ while it is 0.89 with $\mathrm{SSS}_{\mathrm{TOpaz}}$. The 
distribution of errors for $\mathrm{SSS}_{\mathrm{SMOS}}$ А т presents only one mode contrary to $\mathrm{SSS}_{\mathrm{TOPAZ}}$ that present two modes due to the absence of the lower SSS (Figure 14B).

470 between SSS estimates from space and in-situ measurements. In addition, the SMOS SSS

471 uncertainty estimated in the L3 product (see section 2.1.2) seems to be a good indicator of the

472 quality of the considered $\mathrm{SSS}_{\mathrm{SMOS} \mathrm{A}+\mathrm{T}}$ estimate.

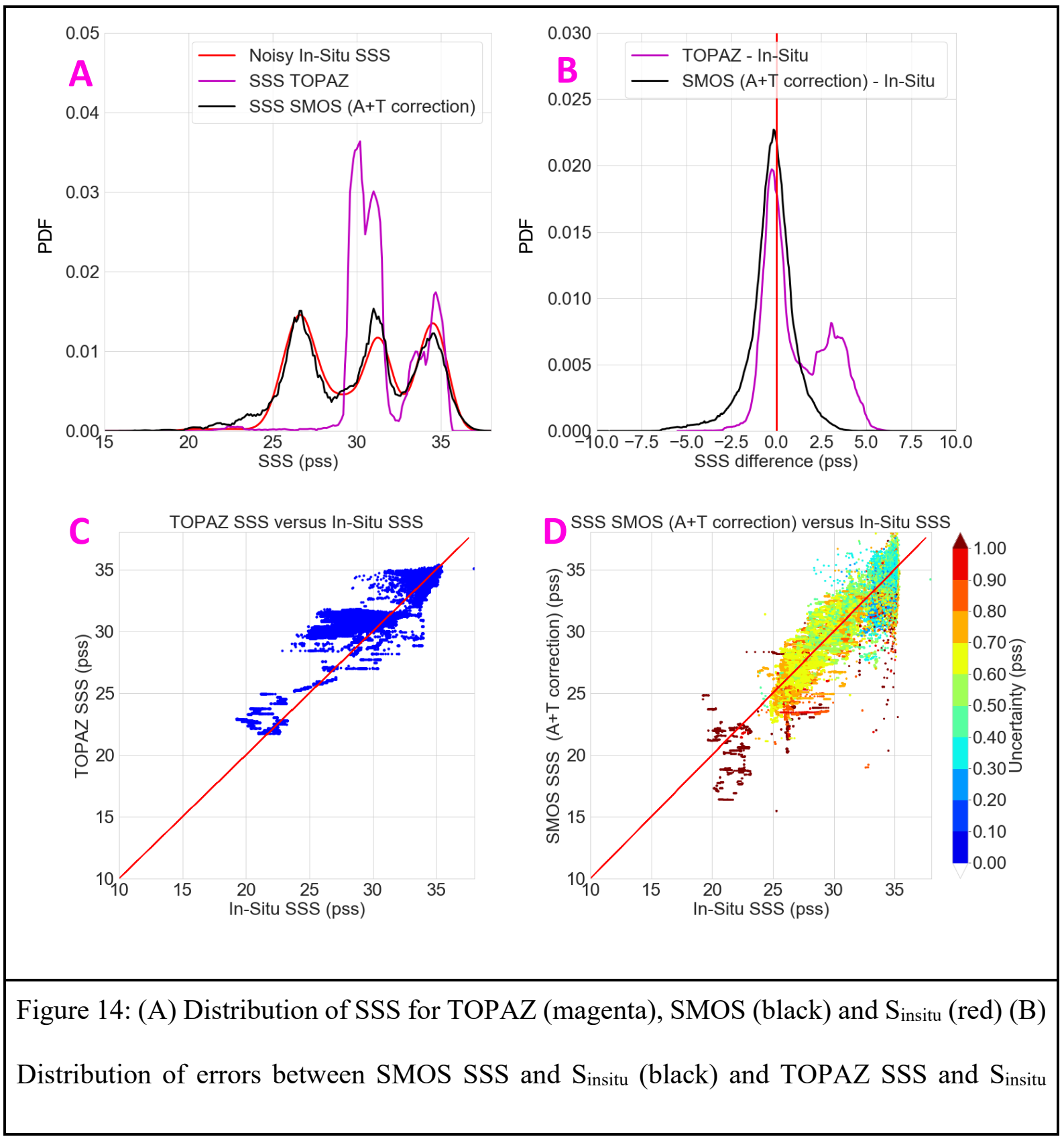


(magenta) (C) Scatterplot of TOPAZ SSS versus $\mathrm{S}_{\text {insitu; }}$ (D) Scatterplot of SMOS SSS versus $\mathrm{S}_{\text {insitu }}$ with SMOS theoretical uncertainty coded in color.

473

474

475

476

477

478

479

480

481

482

483

484

485

\subsection{Interannual variability}

We then compare the $\mathrm{SSS}_{\mathrm{SMOS}} \mathrm{A}_{\mathrm{T}}$ interannual variability to $\mathrm{SSS}_{\mathrm{TOPAZ}}$ interannual variability. For each year between 2011 to 2017 we average SSS between August and October in order to consider the season with the lowest sea ice coverage in the Arctic Ocean. The average is weighted by the uncertainty value of each L3 SSS estimate. Figure 15 is a comparison for the 2012, 2013 and 2014 years and Figure 16 is a comparison for the 2015, 2016 and 2017 years.

Contrary to TOPAZ that provides an SSS value for each pixel of the Arctic Ocean, $\mathrm{SSS}_{\mathrm{SmOS}}$ ${ }_{A}+\mathrm{T}$ coverage depends on the sea ice extent. For the comparison we take into account $\mathrm{SSS}_{\mathrm{TOPAZ}}$ only when a SSS $\mathrm{SmoS}$ A+T value exists.

A good overall consistency in the Arctic Ocean is observed between $\mathrm{SSS}_{\mathrm{SMOS}} \mathrm{A}+\mathrm{T}$ and $\mathrm{SSS}_{\mathrm{TOPAZ}}$ interannual variations. However, $\mathrm{SSS}_{\mathrm{SmOS}} \mathrm{A}+\mathrm{T}$ exhibits a higher interannual and spatial variability than $\mathrm{SSS}_{\mathrm{TOPAZ}}$. Furthermore, some areas behave differently with $\mathrm{SSS}_{\mathrm{SMOS} \mathrm{A}+\mathrm{T}}$ in comparison with $\mathrm{SSS}_{\mathrm{TOPAZ}}$. For the whole period and as observed previously regarding $\mathrm{S}_{\mathrm{insitu}}$ (Table 2), the freshening of the Beaufort gyre is strongly underestimated with $\mathrm{SSS}_{\mathrm{TOPAZ}}$ compared to $\mathrm{SSS}_{\mathrm{SmOS}} \mathrm{A}+\mathrm{T}$. The variability and spatial extent of Arctic Ocean river plumes also differ strongly between $\mathrm{SSS}_{\mathrm{TOPAZ}}$ and $\mathrm{SSS}_{\mathrm{SmOS}} \mathrm{A}+\mathrm{T}$. In the Kara Sea, the locations and strength of the $\mathrm{Ob}$ and the Yenissei river plumes are highly variable from one year to the other (freshening minimum in 2012 and 2016, maximum in 2015). This variability is captured by $\mathrm{SSS}_{\mathrm{TOPAZ}}$ and $\mathrm{SSS}_{\mathrm{SMOS} \mathrm{A}}{ }_{\mathrm{T}}$, but with larger amplitudes in $\mathrm{SSS}_{\mathrm{SMOS} \mathrm{A}^{\mathrm{T}}}$, in particular in 2015. River plume propagation to the north or/and to the east in the East-Siberian Sea are not captured

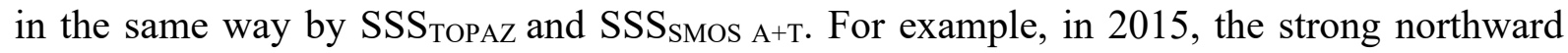
advection of Lena river plume shown by $\mathrm{SSS}_{\mathrm{SmOS}} \mathrm{A}^{+\mathrm{T}}$ is not observed with $\mathrm{SSS}_{\mathrm{TOPAZ}}$. Similar 
496 observations are made in the Bering strait with the entry of Pacific water or low SSS water in 497 the Greenland Sea and in the Baffin Bay.

498 Contrary to SSS TOPAz, freshening patterns are observed at the northern boundary of the field 499 covered by $\mathrm{SSS}_{\mathrm{SmOS} A+\mathrm{T}}$ (limitation due to the presence of permanent ice). The cause of this 500 freshening is not totally explained and may come from a real freshening due to ice melting or 501 an imprint of sea ice due to an imperfect filtering of sea ice. 


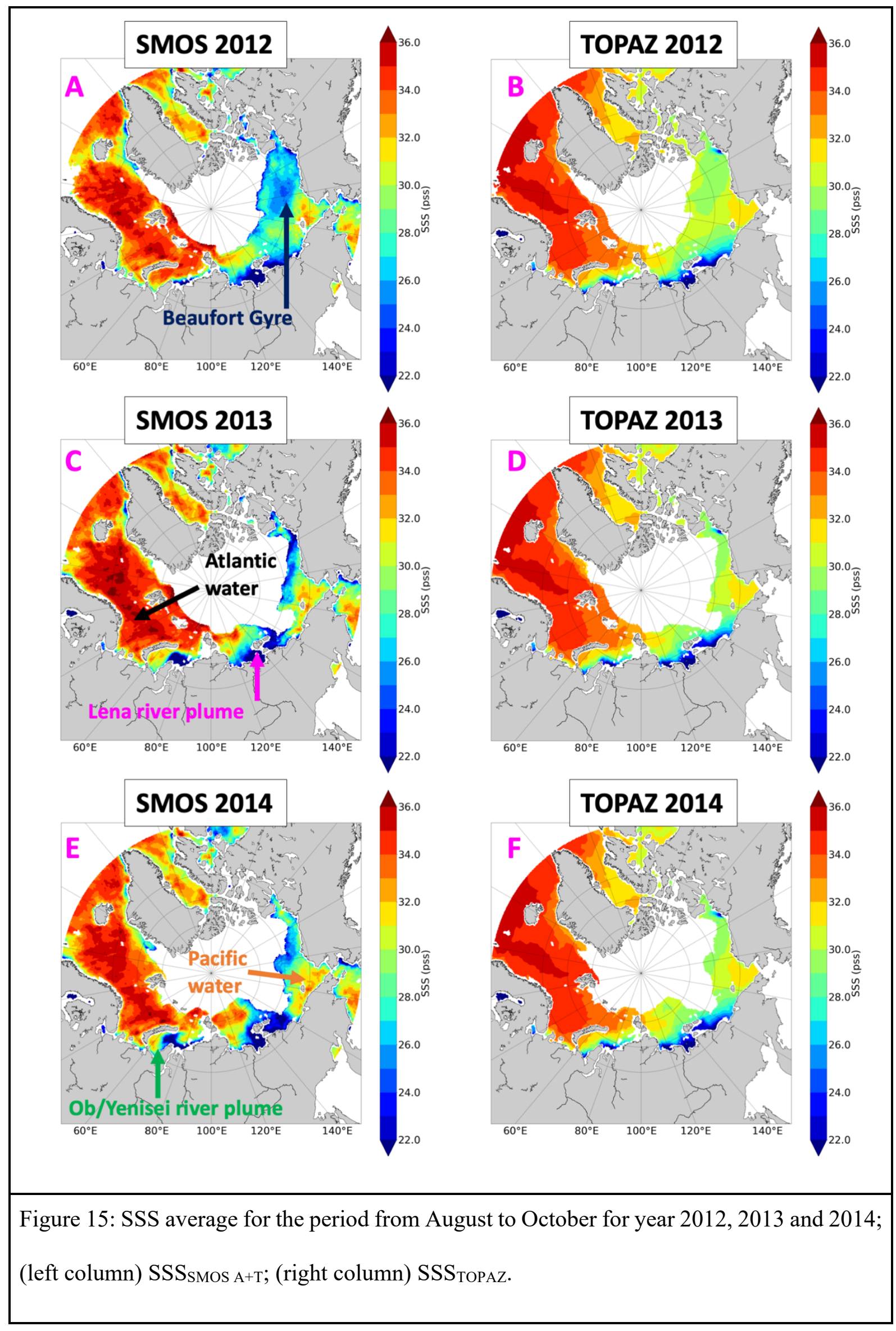



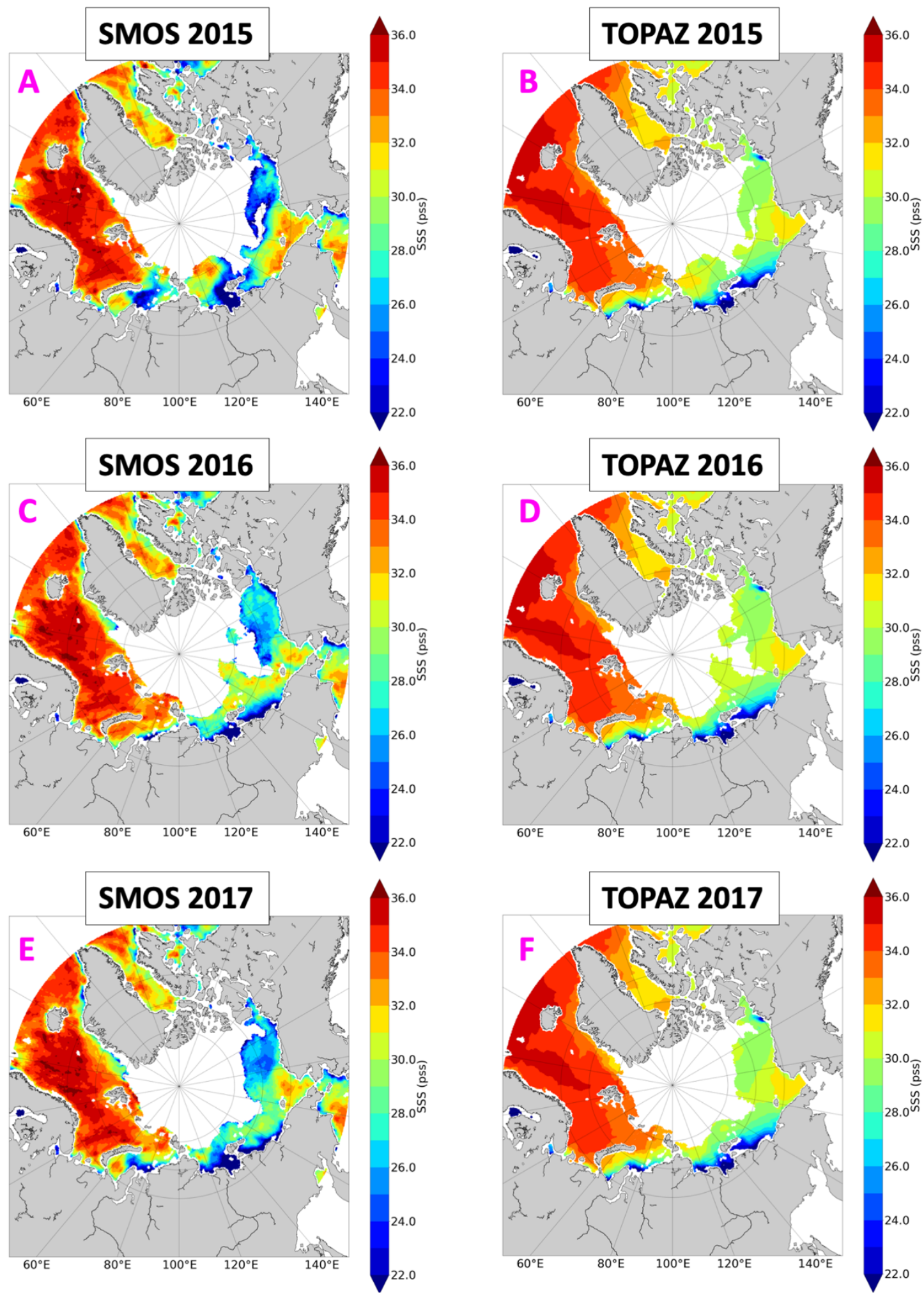

Figure 16: SSS average from August to October for year 2015, 2016 and 2017; (left column) $\mathrm{SSS}_{\mathrm{SMOS} \mathrm{A}+\mathrm{T}}$; (right column) $\mathrm{SSS}_{\mathrm{TOPAZ}}$. 
504 7. Conclusion and discussion

505 We present a methodology that significantly improves SSS estimates in the Arctic Ocean.

506 It is applied to SMOS L3 SSS derived from ESA level 2 operational processing (L2 OS v662).

507 In a first step, the difference between a pseudo dielectric constant, Acard, retrieved from

508 SMOS measurements and a theoretical Acard estimated with KS model is used to efficiently

509 filter out biased SSS in pixels partially covered by sea ice.

510 A global correction (1.29 pss) over the whole Arctic Ocean is applied, to take into account

511 the uncertainty associated with the absolute calibration of the measurements.

512 The Acard difference is then used as a metric of the biases in the KS model for the dielectric

513 constant of sea water. An additional SST correction derived using an external SST satellite

514 product, $\mathrm{SST}_{\mathrm{REMSS}}$, is performed. The latter is motivated by observed difference of statistical

515 distribution between $\mathrm{SST}_{\mathrm{ECMWF}}$ (which is used in the retrieval of SSS) and $\mathrm{T}_{\text {insitu. }}$ The correction

516 strongly improves the SMOS SSS estimate. This relies on the importance of correcting prior

517 SST in cold regions where the sensitivity of TB to SSS is low. The effect of the SST correction

518 is particularly noticeable in the Arctic Seas where river inflows generate strong SST gradients

519 associated with strong SSS gradients: after this SST correction the SSS variability becomes

520 much closer to the observations (Figure 14a).

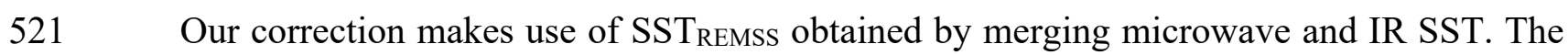
522 use of the REMSS “microwave only" OI SST gives very close statistical results (Appendix-F). 523 Nevertheless, statistics obtained with SST REMSS "microwave only" are slightly better for two 524 reasons: 1 / the sea ice filtering of SST REMSS "microwave only" is more stringent than the one of $525 \mathrm{SST}_{\text {REMSS }}$ and, in some cases, than the one based on SMOS Acard; 2/ $\mathrm{SST}_{\text {REMSS "microwave }}$ 526 only" are not provided too close from the coast where SSS uncertainty is higher. 
Our correction does not reveal the complexity of biases resulting from land/sea contrast,

528 but land/sea bias correction in the Arctic Ocean is a challenging issue that needs to be 529 investigated in further studies. It is likely one of the reasons why SSS calibration needs to be 530 adjusted. Another limitation of the correction methodology is that we only consider issues with 531 SST and dielectric constant model : surface roughness effects linked to e.g. wind in limited 532 fetch areas or to surfactants could also play a role, but these effects were out of the scope of our 533 study.

534 The quality of our new product is assessed by comparison with various in-situ 535 measurements (Argo, Underway TSG and CTD casts) and with an ocean model outputs 536 (TOPAZ). In-situ measurements cover a large range of SSS. The in-situ salinity measurement 537 depth (between $1 \mathrm{~m}$ and $10 \mathrm{~m}$ ) is shown to have a strong impact on the difference between 538 SSS $_{\mathrm{SmOS}}$ and $\mathrm{S}_{\text {insitu, }}$ especially in low SSS areas (e.g., rivers plumes) that are often very stratified 539 in salinity close to the surface. Hence only $S_{\text {insitu }}$ between $1 \mathrm{~m}$ and $5 \mathrm{~m}$ depth are retained for the 540 validation.

541 The corrected SSS better performs than TOPAZ reanalysis, essentially in areas of large 542 temporal and spatial variability. Over the whole Arctic Ocean, STDD between weekly corrected 543 SMOS SSS and $\mathrm{S}_{\text {insitu }}$ is of 1.28 pss, while STDD between TOPAZ SSS and $\mathrm{S}_{\text {insitu }}$ is of 1.86 544 pss. The statistics of the comparisons with $\mathrm{S}_{\text {insitu }}$ in the various regions (the Beaufort, Chukchi, 545 Laptev and Barents Seas, and an Atlantic Area) are more stable from one study area to another 546 with corrected SMOS SSS than with TOPAZ SSS. SMOS STDD vary between 0.94 pss and 5471.23 pss, while TOPAZ STDD vary between 0.50 pss and 1.89 pss. The mean differences 548 obtained with SMOS SSS vary between -1.28 pss and 0.11 pss while the ones obtained with 549 TOPAZ SSS vary between -0.19 pss and 3.67 pss. SMOS SSS captures high variability in fresh 550 Arctic Seas with a favorable signal to noise ratio as shown by high correlation levels on the 


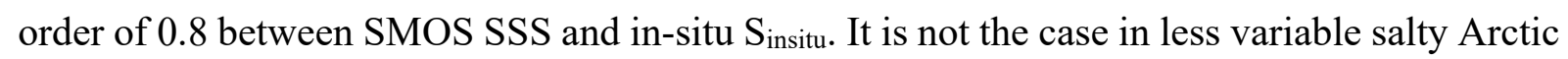

552 Seas (Table 2).

553 While collocations with in-situ measurements, in particular underway TSG from research 554 vessel, demonstrates SMOS ability to capture SSS (temporal and spatial) variability at short 555 scale, SMOS SSS seasonal averages bring a new perspective on the SSS variability in the Arctic 556 Ocean. Compared with the TOPAZ reanalysis, it shows a larger variability in river plumes and 557 differences of pattern, e.g. in the Beaufort gyre (Figure 15 and 16). These observations suggest 558 complementarity between SMOS SSS and TOPAZ reanalysis products. This was already demonstrated by Xie et al (2019) for Arctic SSS produced at the Barcelona Expert center, but 560 this is even more evident with this new product in very variable Arctic Seas (Appendix-H, 561 Laptev Sea and Beaufort Sea).

562 The presented SSS product demonstrates valuable performances compared to other SSS 563 products in Arctic Ocean (Appendix-H). It provides avenues for improvement in the ESA L2 564 OS processor concerning the detection of sea ice, the correction of dielectric constant and SST 565 related flaws. Moreover, additional work is needed in areas with lower SSS variability and RFI 566 contamination as in the North Atlantic. In addition to the methods presented in this study, a 567 correction for the land/sea contamination and the latitudinal biases as presented by Boutin et al 568 (2018) or/and an optimal interpolation using complementarity between SMOS SSS and in-situ 569 measurements could further improve SSS derived from SMOS mission in the Arctic Ocean.

570 This study highlights the importance of sea ice filtering. In that respect, increasing the 571 spatial resolution of L-band interferometric radiometer measurements to $10 \mathrm{~km}$, as proposed by 572 the SMOS-HR project (Rodríguez-Fernández et al., 2019), would greatly help to better filter 573 the ocean areas partially covered by sea ice and would allow to get closer to the ice edge and to 574 land. 
This study highlights the importance of using an SST prior consistent with L-Band

576 radiometric measurement for SSS retrieval in the Arctic Ocean. Ideally, the prior SST should

577 be measured at the same spatial resolution and at the same time as the L-band measurement.

578 One of the major CIMR (Copernicus Image Microwave Radiometer, Kilic et al., 2018) mission

579 goal over the ocean is to provide simultaneous SSS and SST measurements but at different

580 spatial resolution (SSS from the L-Band TB at $\sim 60 \mathrm{~km}$ resolution and SST from the C/X-band

581 channels at $\sim 15 \mathrm{~km}$ ). Joined and simultaneous SSS/SST estimates at the same resolution than

582 the L-Band channel, i.e., $36 \times 60 \mathrm{~km}^{2}$ will therefore be available from this sensor but at a rather

583 low spatial resolution for the estimate of the SSS field. Complementarily, SMOS-HR

584 interferometric mission goal is to provide L-Band TB and therefore SSS at a spatial resolution

$585(\sim 10 \mathrm{~km})$ close to CIMR SST resolution but it won't include an independent SST sensor. Hence

586 combining measurements from both missions would very likely improve SSS fields estimates

587 in the Arctic Ocean.

588 This study is limited to the analysis of SSS provided by the SMOS satellite mission in 589 the Arctic Ocean. Nevertheless, during the period considered in this study, two other satellite 590 missions, SMAP and Aquarius, have monitored SSS over the global ocean. The CCI+SSS 591 project run as a part of ESA Climate Change Initiative aims at generating improved and consistent multi-satellites SSS fields and should bring a decisive improvement to the level 4 SSS maps, especially in the Arctic Ocean due to the short revisit time allowed by the orbit 594 configuration of these satellites. The avenue for SMOS processing improvement that we 595 propose should also benefit to the CCI+SSS products that incorporate SMOS measurements.

Acknowledgments

598 AS is supported by a SU Ph. D. grant. This work was supported by CNES-TOSCA 'SMOS599 Ocean', CNES Centre Aval de Traitement des Données SMOS (CATDS) and ESA 'Expert 
600 Support Laboratory for level 2 Ocean Salinity' projects. AT acknowledges financial support 601 from the Ministry of Science and Higher Education of the Russian Federation, project

602

603

604 References

605 Björk, G. 2017. CTD data from the SWERUS-C3 expedition 2014 in the Arctic 606 RFMEFI61617X0076.

\section{Ocean. PANGAEA, https://doi.org/10.1594/PANGAEA.884144.}

Brucker, L., Dinnat, E. P., and Koenig, L. S. 2014. Weekly gridded Aquarius L-band radiometer/scatterometer observations and salinity retrievals over the polar regions, Part 2: Initial product analysis, The Cryosphere, 8, 3, 915-930, https://www.thecryosphere.net/8/915/2014/, doi:10.5194/tc-8-915-2014.

Boutin, J., Chao, Y., Asher, W.E., Delcroix, T., Drucker, R., Drushka, K., Kolodziejczyk, N., Lee, T., Reul, N., Reverdin, G., Schanze, J., Soloviev, A., Yu, L., Anderson, J., Brucker, L., Dinnat, E., Santos-Garcia, A., Jones, W.L., Maes, C., Meissner, T., Tang, W., Vinogradova, N., Ward, B. 2016. Satellite and In Situ Salinity: Understanding Near-Surface Stratification and Subfootprint Variability. Bull. Amer. Meteor. Soc., 97, 1391-1407, https://doi.org/10.1175/BAMS-D-15-00032.1

Boutin, J., Vergely, J. L., Marchand, S., D’Amico, F., Hasson, A., Kolodziejczyk, N., Reul, N., Reverdin, G., and Vialard, J. 2018. New SMOS Sea Surface Salinity with reduced systematic errors and improved variability, Remote Sens. Environ., 214, 115-134, https://doi.org/10.1016/j.rse.2018.05.022.

Carmack, E. C., The alpha/beta ocean distinction: A perspective on freshwater fluxes, convection, nutrients and productivity in high-latitude seas, Deep Sea Research Part II: Topical Studies in Oceanography, Volume 54, Issues 23-26, 2007, Pages 2578-2598, ISSN 0967-0645, https://doi.org/10.1016/j.dsr2.2007.08.018. 
625 Carmack, E. C., et al. 2016. Freshwater and its role in the Arctic Marine System : Sources, 626 disposition, storage, export, and physical and biogeochemical consequences in the Arctic and 627 global oceans, J. Geophys. Res. Biogeosci., 121, 675-717, doi:10.1002/2015JG003140.

628 Chassignet, E.P., Hurlburt, H.E., Metzger, E.J., Smedstad, O.M., Cummings, J.A., Halliwell, 629 G.R., Bleck, R., Baraille, R., Wallcraft, A.J., Lozano, C., Tolman,H.L., Srinivasan, A., Hankin, 630 S., Cornillon, P., Weisberg, R., Barth, A., He, R., Werner, F., Wilkin, J. 2009. US GODAE: 631 Global ocean prediction with the HYbrid Coordinate Ocean Model (HYCOM). Oceanography 632 22(2):64-75, doi:10.5670/oceanog.2009.39.

633 Dinnat, E. P., Le Vine, D. M., Boutin, J., Meissner, T., Lagerloef, G. 2019. Remote Sensing, 634 2072-4292, 11, 7, 750, Remote Sensing of Sea Surface Salinity: Comparison of Satellite and In 635 Situ Observations and Impact of Retrieval Parameters, doi:10.3390/rs11070750, 636 https://www.mdpi.com/2072-4292/11/7/750.

637 Donlon, C.J., Martin, M., Stark, J., Roberts-Jones, J., Fiedler, E., Wimmer, W. 2012. The 638 operational sea surface temperature and sea ice analysis (OSTIA) system. RemoteSens. 639 Environ. 116, 140-158.https://doi.org/10.1016/j.rse.2010.10.017.

640 ECMWF. 2016. IFS Documentation CY41R2. Part II : Data Assimilation. IFS Documentation. 641 ECMWF.

642 Font, J., Camps, A., Borges, A., Martin-Neira, M., Boutin, J., Reul, N.,Kerr, Y. H., Hahne, A., 643 Mecklenburg, S. 2010. SMOS: The Challenging Sea Surface Salinity Measurement From 644 Space, Proceedings of the IEEE, 98(5), 649-665, doi:10.1109/jproc.2009.2033096.

645 Haine, T. W., Curry, B., Gerdes, R., Hansen, E., Karcher, M., Lee, C., Rudels, B., Spreen, G. , 646 de Steur, L., Stewart, K. D. and Woodgate, R. 2015. Arctic freshwater export: Status, 647 mechanisms, and prospects, Global and Planetary Change, 125, pp. 13-35. doi: $648 \quad$ 10.1016/j.gloplacha.2014.11.013. 
649 Høyer J.L., Karagali, I., Dybkjær, G., Tonboe, R., Multi sensor validation and error 650 characteristics of Arctic satellite sea surface temperature observations, Remote Sensing of 651 Environment, Volume 121, 2012, Pages 335-346, ISSN 0034-4257, 652 https://doi.org/10.1016/j.rse.2012.01.013.

653 IPCC, 2018: Summary for Policymakers. In: Global warming of $1.5^{\circ} \mathrm{C}$. An IPCC Special 654 Report on the impacts of global warming of $1.5^{\circ} \mathrm{C}$ above pre-industrial levels and related global 655 greenhouse gas emission pathways, in the context of strengthening the global response to the 656 threat of climate change, sustainable development, and efforts to eradicate poverty [V. Masson657 Delmotte, P. Zhai, H. O. Pörtner, D. Roberts, J. Skea, P. R. Shukla, A. Pirani, W. Moufouma658 Okia, C. Péan, R. Pidcock, S. Connors, J. B. R. Matthews, Y. Chen, X. Zhou, M. I. Gomis, E. 659 Lonnoy, T. Maycock, M. Tignor, T. Waterfield (eds.)]. World Meteorological Organization, 660 Geneva, Switzerland, $32 \mathrm{pp}$.

661 Ivanov V et al. 2013. NABOS 2013 Arctic Expedition aboard RV “Akademik Fedorov", 662 https://nabos.iarc.uaf.edu/NABOS2/data/registered/2013/metadata/brief_report_2013663 engl.pdf.

664 JAMSTEC (2013) MIRAI MR12-E03 Cruise Data. JAMSTEC. doi:10.17596/0001847 665 (accessed 2019-07-16).

666 JAMSTEC (2013) MIRAI MR13-06 Leg1 Cruise Data. JAMSTEC. doi:10.17596/0001856 667 (accessed 2019-07-16).

668 JAMSTEC (2015) MIRAI MR14-05 Cruise Data. JAMSTEC. doi:10.17596/0001861 669 (accessed 2019-07-16).

670 Kerr, Y. H., et al. 2010. The SMOS Mission : New Tool for Monitoring Key Elements of the 671 Global Water Cycle, Proceedings of the IEEE, 98(5), 666-687.

672 Kilic, L., Prigent, C., Aires, F., Boutin, J., Heygster, G., Tonboe, R. T. et al. 2018. Expected 673 performances of the Copernicus Imaging Microwave Radiometer (CIMR) for an all-weather 
674 and high spatial resolution estimation of ocean and sea ice parameters. Journal of Geophysical

675 Research: Oceans, 123, 7564-7580. https://doi.org/10.1029/2018JC014408

676 Klein, L.A. and Swift, C.T. 1977. An Improved Model for the Dielectric Constant of Sea Water

677 at Microwave Frequencies. IEEE Journal of Oceanic Engineering, 2, 104-

678 111. http://dx.doi.org/10.1109/JOE.1977.1145319.

679 Köhler, J., Sena Martins, M., Serra, N., Stammer, D. 2015. Quality assessment of spaceborne 680 sea surface salinity observations over the northern North Atlantic, J. Geophys. Res. Oceans, 681 120, 94-112, doi:10.1002/ 2014JC010067.

682 Lagerloef, G., et al. 2008) The Aquarius/SAC-D mission: Designed to meet the salinity remote 683 sensing challenge Oceanography, 21(1), 68-81. Lind, S., Ingvaldsen, R. B., Furevik, T., 2018. 684 Arctic warming hotspot in the northern Barents Sea linked to declining sea-ice import. Nature 685 Climate Change. https://doi.org/10.1038/s41558-018-0205-y.

686 Makhotin, M., Ivanov, V. 2018. Physical oceanography measured with CTD/Watersampler687 system during PU2012 to the Barents Sea in 688 2012. PANGAEA, https://doi.org/10.1594/PANGAEA.895269.

689 Makhotin, M., Ivanov, V. 2018. Physical oceanography measured with CTD/Watersampler690 system during PU2013 to the Barents Sea in 691 2013. PANGAEA, https://doi.org/10.1594/PANGAEA.895270.

692 Makhotin, M., Ivanov, V. 2018. Physical oceanography measured with CTD/Watersampler693 system during PU2014 to the Barents Sea in 694 2014. PANGAEA, https://doi.org/10.1594/PANGAEA.895271.

695 Marquardt, D. W., "An algorithm for least-squares estimation of non-linear parameters," J. Soc. 696 Ind. Appl. Math, vol. 11, pp. 431-441, 1963.

697 Matsuoka, A., Babin, M., Devred E. C. 2016. A new algorithm for discriminating water sources 698 from space: A case study for the southern Beaufort Sea using MODIS ocean color and SMOS 
699

700

701

702

703

704

705

706

707

708

709

710

711

712

713

714

715

716

717 Expedition

718

719

720

721

722

723

salinity data, Remote Sensing of Environment, Volume 184, Pages 124-138, ISSN 0034-4257, https://doi.org/10.1016/j.rse.2016.05.006.

Meissner, T., Wentz, F. J., Scott, J., Vazquez-Cuervo, J. 2016. Sensitivity of Ocean Surface

Salinity Measurements From Spaceborne L-Band Radiometers to Ancillary Sea Surface Temperature, in IEEE Transactions on Geoscience and Remote Sensing, vol. 54, no. 12, pp. 7105-7111, doi: 10.1109/TGRS.2016.2596100.

Olmedo, E., Gabarró, C., González-Gambau, V., Martínez, J., Ballabrera-Poy, J., Turiel, A., Portabella, M., Fournier, S., and Lee, T.2018. Seven Years of SMOS Sea Surface Salinity at High Latitudes: Variability in Arctic and Sub-Arctic Regions, Remote Sens., 10, 1772, https://doi.org/10.3390/rs10111772.

Peralta-Ferriz, C., Woodgate, R. A. 2015. Seasonal and interannual variability of pan-Arctic surface mixed layer properties from 1979 to 2012 from hydrographic data, and the dominance of stratification for multiyear mixed layer depth shoaling, Progress in Oceanography, Volume 134, Pages 19-53, ISSN 0079-6611, https://doi.org/10.1016/j.pocean.2014.12.005.

Piepmeier J. R. et al. 2017. SMAP L-Band Microwave Radiometer : Instrument Design and First Year on Orbit," in IEEE Transactions on Geoscience and Remote Sensing, vol. 55, no. 4, pp. 1954-1966, doi: 10.1109/TGRS.2016.2631978.

https://nabos.iarc.uaf.edu/NABOS2/data/registered/2015/metadata/Report_2015.pdf.

Regan, H. C., Lique, C., Armitage, T. W. K. 2019. The Beaufort Gyre extent, shape, and location between 2003 and 2014 from satellite observations, Journal of Geophysical Research: Oceans, 124, 844- 862. https://doi.org/10.1029/2018JC014379.

Reul, N., Grodsky, S.A., Arias, M., Boutin, J. , Catany, R., Chapron, B., D'Amico, F., Dinnat, E., Donlon, C., Fore, A., Fournier, S., Guimbard, S., Hasson, A., Kolodziejczyk, N., Lagerloef, 
G., Lee, T., Le Vine, D.M., Lindstrom, E., Maes, C., Mecklenburg, S., Meissner, T., Olmedo,

E., Sabia, R., Tenerelli, J., Thouvenin-Masson, C., Turiel, A., Vergely, J.L., Vinogradova, N., overview of the first decade of observation (2010-2019), Remote Sensing of Environment, Volume 242, 2020, 111769, ISSN 0034-4257, https://doi.org/10.1016/j.rse.2020.111769.

Rodríguez-Fernández, Anterrieu, et al. 2019. SMOS-HR: A high resolution L-band passive radiometer for Earth Science and applications, IEEE Symposium on Geoscience and Remote Sensing 2019, p. 8392-8395

Sakov, P., Counillon, F., Bertino, L., Lisæter, K. A., Oke, P. R., and Korablev, A.: TOPAZ4: an ocean-sea ice data assimilation system for the North Atlantic and Arctic, Ocean Sci., 8, 633656, https://doi.org/10.5194/os-8-633-2012, 2012.

Shiklomanov, I. A., et al. 1998. World Water Resources. A new appraisal and assessment for the $21^{\mathrm{ST}}$ century. United Nations, Educational, Scientific and Cultural Organization. and Bio Analysis and Forecasting Products. Copernicus Marine Environment Monitoring Service.

740 Stroh, J. N., Panteleev, G., Kirillov, S., Makhotin, M., Shakhova, N. 2015. Sea-surface 741 temperature and salinity product comparison against external in situ data in the Arctic Ocean, J.

742 Geophys. Res. Oceans, 120, 7223-7236, doi:10.1002/2015JC011005.

743 Tang, W., Yueh, S., Yang, D., Fore, A., Hayashi, A., Lee, T., Fournier, S., Holt, B. 2018. The 744 Potential and Challenges of Using Soil Moisture Active Passive (SMAP) Sea Surface Salinity 745 to Monitor Arctic Ocean Freshwater Changes, Remote Sensing,10.3390/rs10060869.

746 Tarasenko, A., Supply, A., Kusse-Tiuz, N., Ivanov, V., Makhotin, M., Tournadre, J., Chapron, 747 B., Boutin, J., and Kolodziejczyk, N.: Surface waters properties in the Laptev and the East- 
748 Siberian Seas in summer 2018 from in situ and satellite data, Ocean Sci. Discuss., 749 https://doi.org/10.5194/os-2019-60, in review, 2019.

750 Ulaby, F., Moore, R., Fung, A. 1990. Microwave Remote Sensing: Active and Passive, vol.3, 751 Artech House, Boston, Mass.

752 Vinogradova, N., Lee, T., Boutin, J., Drushka, K., Fournier, S., Sabia, R., Stammer, D., Bayler, 753 E., Reul, N., Gordon, A., Melnichenko, O., Li, L., Hackert, E., Martin, M., Kolodziejczyk, N., 754 Hasson, A., Brown, S., Misra, S., Lindstrom, E. 2019. Satellite Salinity Observing System: 755 Recent Discoveries and the Way Forward. Front. Mar. Sci. 6: 243. Doi: $756 \quad 10.3389 /$ fmars.2019.00243.

757 Waldteufel, P., Vergely, J. L., Cot, C., "A modified cardioid model for processing multiangular 758 radiometric observations," IEEE Transactions on Geoscience and Remote Sensing, vol. 42, pp. 759 1059-1063, 2004.

760 Yueh, S.H., West, R., Wilson, W. J., Li, F. K., Njoku, E. G., Rahmat- Samii, Y. 2001. Error 761 sources and feasibility for microwave remote sensing of ocean surface salinity. IEEE 762 Transactions on Geoscience and Remote Sensing, vol. 39, no. 5, pp. 1049-1060.

763 Xie, J., Raj, R. P., Bertino, L., Samuelsen, A., Wakamatsu, T. 2019. Evaluation of Arctic Ocean 764 surface salinities from the Soil Moisture and Ocean Salinity (SMOS) mission against a regional 765 reanalysis and in situ data, Ocean Science, 15, 5, 1191--1206, https://www.ocean766 sci.net/15/1191/2019/, 10.5194/os-15-1191-2019.

768 Appendix-A: Acard retrieval in the SMOS level 2 processor

769 As shown by Waldteufel et al. (2004), simultaneous retrieval of the real, e', and imaginary part, 770 e", of dielectric constant from SMOS TB is an ill posed problem as the cost function, rather 771 than a single minimum, exhibits a minimum valley, that can be represented analytically using 772 a modified cardioid model. After carrying out the following change of variable: 


$$
\begin{aligned}
& \mathrm{e}^{\prime}=\text { Acard }(1+\cos (\text { Ucard })) \cos (\text { Ucard })+\text { Bcard } \\
& \mathrm{e}^{\prime \prime}=\text { Acard }(1+\cos (\text { Ucard })) \sin (\text { Ucard })
\end{aligned}
$$

773 which is equivalent to:

$$
\begin{aligned}
& \text { Acard }=\text { mcard }^{2} /\left(\text { mcard }+e^{\prime}-\text { Bcard }\right) \\
& \text { Ucard }=\tan ^{-1}\left(e^{\prime \prime} /\left(e^{\prime}-\text { Bcard }\right)\right) \\
& \text { with: mcard }=\left(\left(e^{\prime}-\text { Bcard }\right)^{2}+e^{\prime 2}\right)^{1 / 2}
\end{aligned}
$$

774 Bcard corresponds to the observed offset between the observed modified cardioid and the true 775 analytical formulation for a cardioid model. With Bcard $=0.8$ (optimal value that minimizes 776 the retrieval error on Acard), it is possible to retrieve the parameter Acard with good accuracy: 777 a minimum of $\chi^{2}$ is seen as a vertical line corresponding to a constant value of Acard and various 778 values of Ucard. Local minima of $\chi^{2}$ are also observed for unrealistic negative values of Acard; as it will be described in the following, retrieval of such negative values are avoided by taking an error on prior Acard over the ocean of 20 units or by initiating the retrieval with low Acard value as low card are much better constrained.

782 It is clear that the minimization of $\chi^{2}$ parameter does not allow to retrieve a single pair of ( $\left(\mathrm{e}^{\prime}\right.$, 783 e") while it allows to retrieve a single value of Acard, Ucard remaining undetermined. We found that initiating the retrieval with low Acard prior value $\left(\right.$ Acard $\left.^{\text {prior }}=1\right)$ and large error on Acard ( $\left.\mathrm{s}_{\mathrm{A}_{-} \text {card }}=50\right)$ allows to avoid retrieval of negative Acard values while avoiding biases 786 on low Acard values and gives the same result over ocean pixels as taking Acard ${ }^{\text {prior }}$ deduced 787 from mean SSS and SST. The ESA L2 Ocean Salinity processor retrieves Acard from SMOS Tb corrected from the roughness model plus atmospheric and galactic noise corrections. 
Appendix-B: HEINCKE and POLARSTERN cruise track datasets used in this study

\begin{tabular}{|c|c|}
\hline HEINCKE cruise track HE493 & https://doi.pangaea.de/10.1594/PANGAEA.887938 \\
\hline HEINCKE cruise track HE387 & https://doi.pangaea.de/10.1594/PANGAEA.859752 \\
\hline HEINCKE cruise track HE492 & https://doi.pangaea.de/10.1594/PANGAEA.887937 \\
\hline HEINCKE cruise track HE333 & https://doi.pangaea.de/10.1594/PANGAEA.859705 \\
\hline HEINCKE cruise track HE451-1 & https://doi.pangaea.de/10.1594/PANGAEA.863418 \\
\hline HEINCKE cruise track HE449 & https://doi.pangaea.de/10.1594/PANGAEA.863416 \\
\hline HEINCKE cruise track HE408 & https://doi.pangaea.de/10.1594/PANGAEA.859774 \\
\hline HEINCKE cruise track HE450 & https://doi.pangaea.de/10.1594/PANGAEA.863417 \\
\hline POLARSTERN cruise track ARK- & \\
\hline $\mathrm{XXVI} / 2$ & https://doi.pangaea.de/10.1594/PANGAEA.770035 \\
\hline POLARSTERN cruise track PS109 & https://doi.pangaea.de/10.1594/PANGAEA.889548 \\
\hline POLARSTERN cruise track PS93.2 & https://doi.pangaea.de/10.1594/PANGAEA.863229 \\
\hline POLARSTERN cruise track ARK- & \\
\hline XXVII/1 & https://doi.pangaea.de/10.1594/PANGAEA.802811 \\
\hline POLARSTERN cruise track PS99.1 & https://doi.pangaea.de/10.1594/PANGAEA.873156 \\
\hline POLARSTERN cruise track PS92 & https://doi.pangaea.de/10.1594/PANGAEA.863234 \\
\hline POLARSTERN cruise track ARK- & \\
\hline $\mathrm{XXVII} / 3$ & https://doi.pangaea.de/10.1594/PANGAEA.808835 \\
\hline POLARSTERN cruise track ARK- & \\
\hline $\mathrm{XXVI} / 1$ & https://doi.pangaea.de/10.1594/PANGAEA.770034 \\
\hline
\end{tabular}




\begin{tabular}{|l|l|}
\hline POLARSTERN cruise track ARK- & \\
XXVI/3 & https://doi.pangaea.de/10.1594/PANGAEA.770828 \\
\hline POLARSTERN cruise track ARK- & https://doi.pangaea.de/10.1594/PANGAEA.802812 \\
\hline POLARSTERN cruise track PS107 & https://doi.pangaea.de/10.1594/PANGAEA.889535 \\
\hline POLARSTERN cruise track PS100 & https://doi.pangaea.de/10.1594/PANGAEA.873158 \\
\hline POLARSTERN cruise track PS93.1 & https://doi.pangaea.de/10.1594/PANGAEA.863228 \\
\hline POLARSTERN cruise track PS101 & $\underline{\text { https://doi.pangaea.de/10.1594/PANGAEA.873145 }}$ \\
\hline POLARSTERN cruise track PS99.2 & $\underline{\text { https://doi.pangaea.de/10.1594/PANGAEA.873153 }}$ \\
\hline POLARSTERN cruise track PS86 & $\underline{\text { https://doi.pangaea.de/10.1594/PANGAEA.858880 }}$ \\
\hline
\end{tabular}

793 Appendix-C: difference of repartition of in-situ measurements used in this study between 1-m and 3-m and between 1-m and 5-m.

A

All devices in-situ salinity between 1-m and 3-m

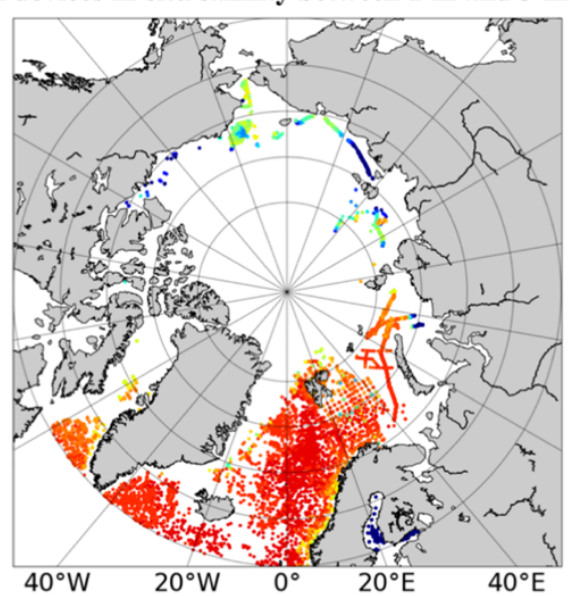

B

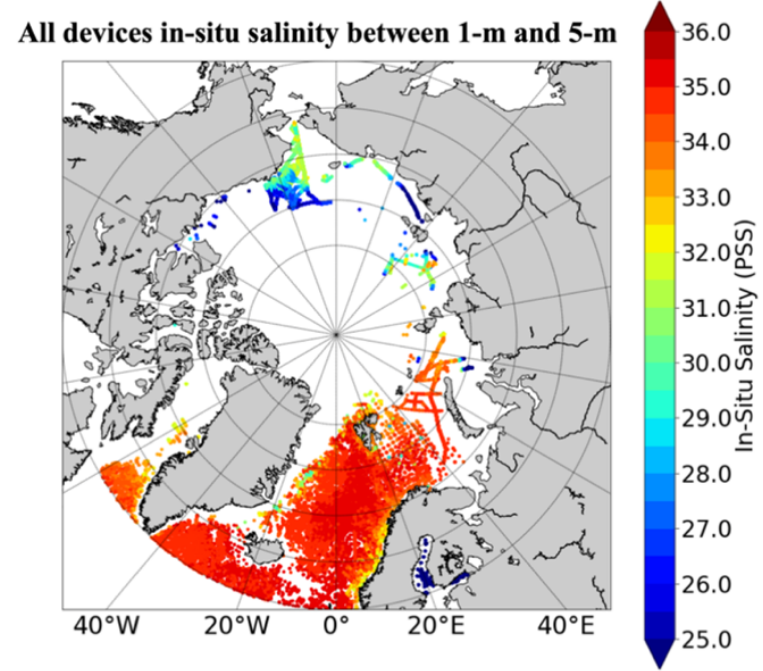

Figure C1: SSS of in-situ measurements used in the study (A) between 1-m and 3-m depth; (B) between 1-m and 5-m depth. 
Density of in-situ measurements

A

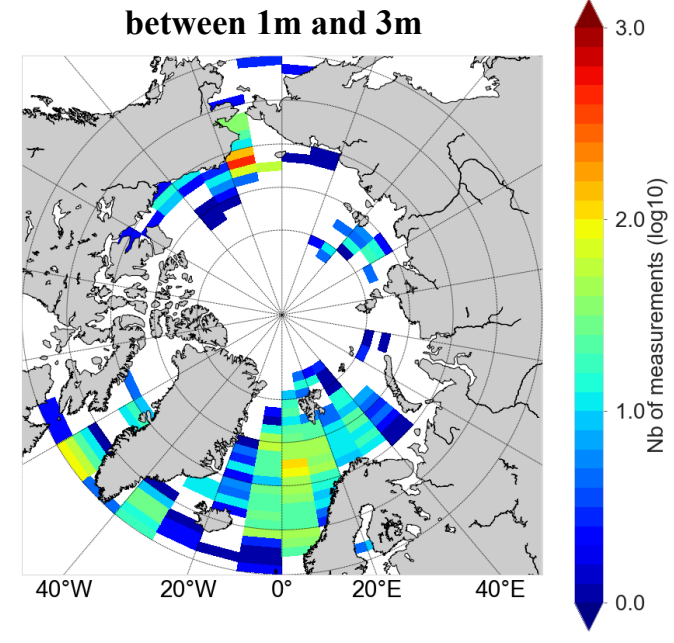

B

\section{Density of in-situ measurements}

between $1 \mathrm{~m}$ and $5 \mathrm{~m}$

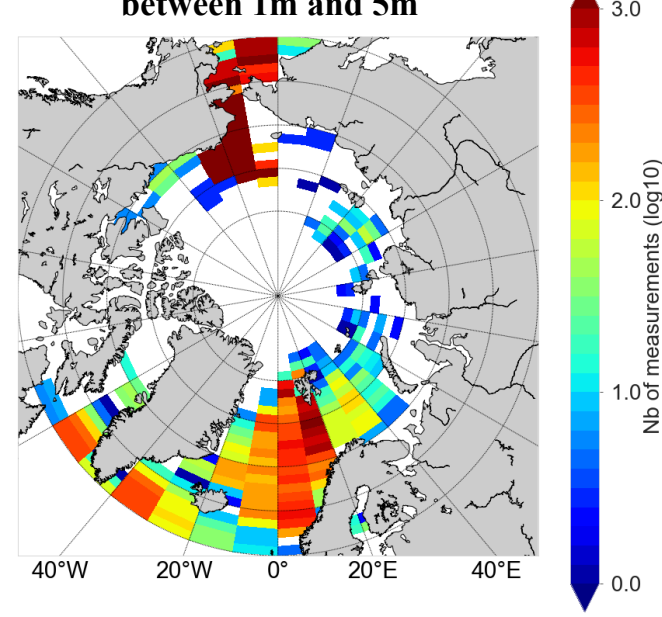

Figure C2: Density of in-situ measurements used in the study (A) between 1-m and 3-m depth; (B) between 1-m and 5-m depth.

797 Appendix-D: example of differences recorded between SST from OSTIA and SST REMSS.

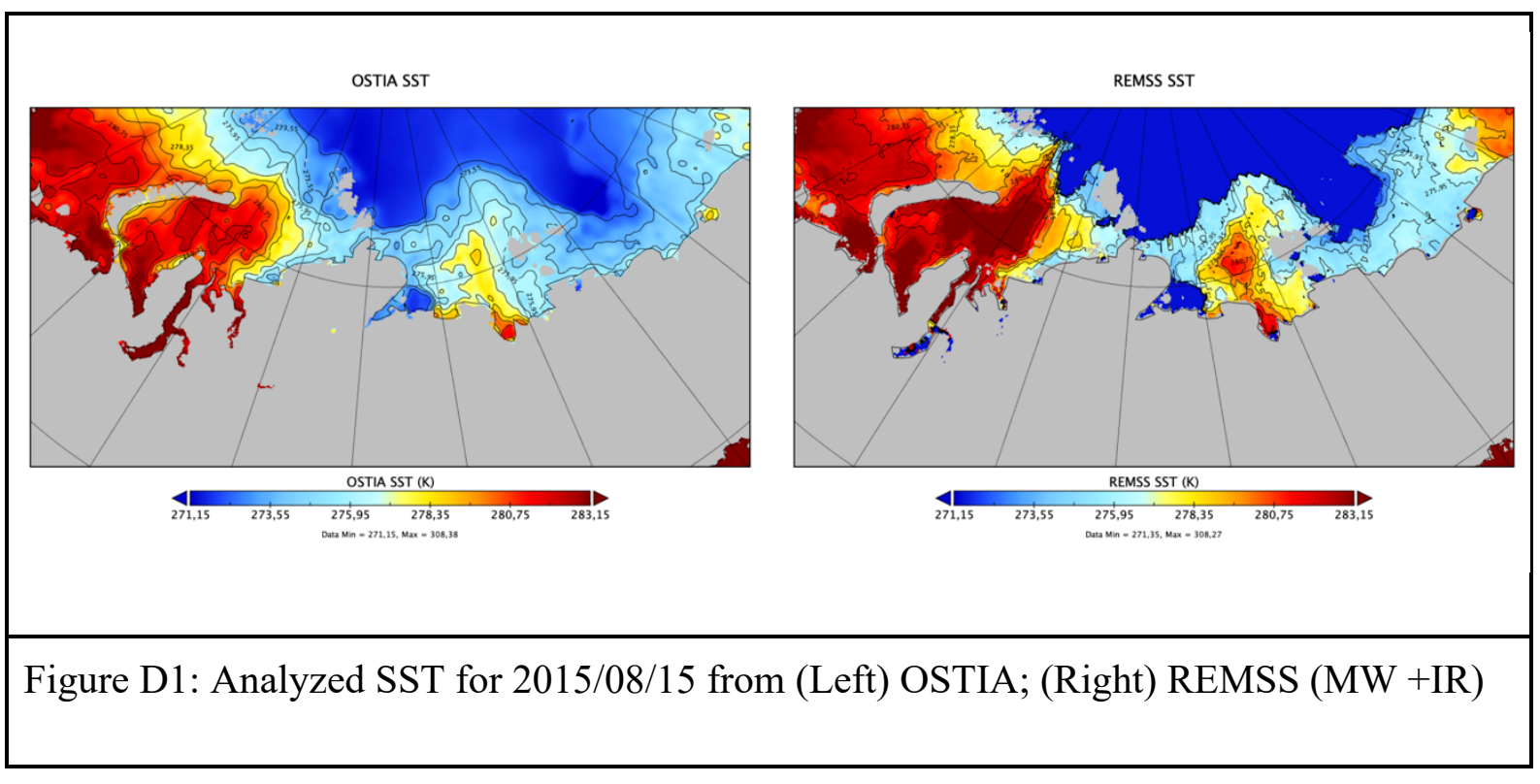

799 Appendix-E: MoD, STDD and $r$ between different versions of SMOS SSS and $\mathrm{S}_{\mathrm{in}-\mathrm{situ}}$ for the

800 different study areas. The number of collocations is equivalent to the table 1 . 


\begin{tabular}{|c|c|c|c|c|c|}
\hline Cases study & $\begin{array}{l}\text { Statistic } \\
\text { indicator }\end{array}$ & $\mathrm{SSS}_{\mathrm{SMOS}}$ & $\mathrm{SSS}_{\mathrm{SMOS} \mathrm{A}}$ & $\mathrm{SSS}_{\mathrm{SMOS} \mathrm{T}}$ & $\mathrm{SSS}_{\mathrm{SMOS} \mathrm{A}+\mathrm{T}}$ \\
\hline \multirow[t]{3}{*}{ Beaufort Sea } & $\mathrm{MoD}(\mathrm{pss})$ & -2.12 & -1.44 & -1.51 & -0.83 \\
\hline & STDD (pss) & 0.96 & 0.98 & 1.08 & 0.88 \\
\hline & $\mathrm{r}$ & 0.86 & 0.83 & 0.83 & 0.88 \\
\hline \multirow[t]{3}{*}{ Chukchi Sea } & $\mathrm{MoD}(\mathrm{pss})$ & -1.50 & -1.28 & -0.49 & -0.28 \\
\hline & STDD (pss) & 1.47 & 1.60 & 1.18 & 1.23 \\
\hline & $\mathrm{r}$ & 0.84 & 0.81 & 0.89 & 0.86 \\
\hline \multirow[t]{3}{*}{ Laptev Sea } & MoD (pss) & -1.97 & -1.39 & -0.43 & 0.12 \\
\hline & STDD (pss) & 1.82 & 2.16 & 1.07 & 1.17 \\
\hline & $\mathrm{r}$ & 0.53 & 0.40 & 0.80 & 0.75 \\
\hline \multirow[t]{3}{*}{ Barents Sea } & $\mathrm{MoD}(\mathrm{pss})$ & -1.59 & -0.24 & -1.49 & -0.17 \\
\hline & STDD (pss) & 0.96 & 0.97 & 0.94 & 0.94 \\
\hline & $\mathrm{r}$ & -0.03 & -0.02 & -0.05 & -0.02 \\
\hline \multirow[t]{3}{*}{ Atlantic Area } & MoD (pss) & -1.29 & -0.55 & -1.25 & -0.51 \\
\hline & STDD (pss) & 1.02 & 1.15 & 1.00 & 1.13 \\
\hline & $\mathrm{r}$ & 0.01 & -0.05 & 0.02 & -0.05 \\
\hline Arctic Ocean & MoD (pss) & -1.54 & -0.77 & -0.99 & -0.27 \\
\hline
\end{tabular}




\begin{tabular}{|c|c|c|c|c|c|}
\hline & STDD (pss) & 1.46 & 1.60 & 1.32 & 1.28 \\
\hline & $\mathrm{r}$ & 0.92 & 0.92 & 0.93 & 0.94 \\
\hline
\end{tabular}

801

802 Appendix-F: MoD, STDD, $r$ and N (number of collocations) between different versions of 803 SMOS SSS or TOPAZ SSS and in-situ measurements for the different study areas (with $804 \mathrm{SSS}_{\mathrm{SMOS} \mathrm{A}}+\mathrm{T}$ derived using $\mathrm{SST}_{\text {REMSS }}$ in black and $\mathrm{SSS}_{\mathrm{SMOS} \mathrm{A}+\mathrm{T}}$ derived using $\mathrm{SST}_{\mathrm{REMSS} \mathrm{MWO}}$ in 805 bold black - collocations are not exactly the same due to a difference of sea ice mask between

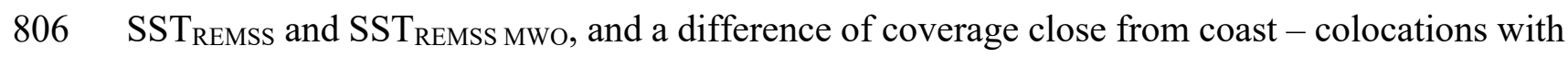
807 in-situ measurements are the same between $\mathrm{SSS}_{\mathrm{SMOS}}, \mathrm{SSS}_{\mathrm{SMOS} \mathrm{A}+\mathrm{T}}$ and $\mathrm{SSS}_{\mathrm{TOPAZ}}$ ).

\begin{tabular}{|c|c|c|c|c|}
\hline Cases study & Statistic indicator & $\mathrm{SSS}_{\mathrm{SMOS}}$ & $\mathrm{SSS}_{\mathrm{SMOS}} \mathrm{A}+\mathrm{T}$ & $\mathrm{SSS}_{\text {TOPAZ }}$ \\
\hline Beaufort Sea & MoD (pss) & $\begin{array}{l}-2.25 \\
\mathbf{- 2 . 2 5}\end{array}$ & $\begin{array}{l}-0.98 \\
\mathbf{- 0 . 9 6}\end{array}$ & $\begin{array}{l}3.99 \\
\mathbf{3 . 9 9}\end{array}$ \\
\hline & STDD (pss) & $\begin{array}{l}0.94 \\
\mathbf{0 . 9 4}\end{array}$ & $\begin{array}{l}0.83 \\
\mathbf{0 . 8 7}\end{array}$ & $\begin{array}{l}1.07 \\
\mathbf{1 . 0 7}\end{array}$ \\
\hline & $\mathrm{r}$ & $\begin{array}{l}0.81 \\
\mathbf{0 . 8 1}\end{array}$ & $\begin{array}{l}0.84 \\
\mathbf{0 . 8 4}\end{array}$ & $\begin{array}{l}0.81 \\
\mathbf{0 . 8 1}\end{array}$ \\
\hline & $\mathrm{N}$ & $\begin{array}{l}3128 \\
\mathbf{3 1 2 8}\end{array}$ & $\begin{array}{l}3128 \\
\mathbf{3 1 2 8}\end{array}$ & $\begin{array}{l}3128 \\
\mathbf{3 1 2 8}\end{array}$ \\
\hline Chukchi Sea & MoD (pss) & $\begin{array}{l}-1.39 \\
\mathbf{- 1 . 3 9}\end{array}$ & $\begin{array}{l}-0.21 \\
\mathbf{- 0 . 2 7}\end{array}$ & $\begin{array}{l}1.94 \\
1.94\end{array}$ \\
\hline & STDD (pss) & 1.30 & 1.08 & 1.79 \\
\hline
\end{tabular}




\begin{tabular}{|c|c|c|c|c|}
\hline & & 1.30 & 1.07 & 1.79 \\
\hline & \multirow[t]{2}{*}{$\mathrm{r}$} & 0.86 & 0.91 & 0.87 \\
\hline & & 0.86 & 0.90 & 0.87 \\
\hline & \multirow[t]{2}{*}{$\mathrm{N}$} & 86917 & 86917 & 86917 \\
\hline & & 86917 & 86917 & 86917 \\
\hline \multirow[t]{8}{*}{ Laptev Sea } & $\mathrm{MoD}(\mathrm{pss})$ & -2.45 & -0.17 & 0.82 \\
\hline & & -2.45 & -0.19 & 0.82 \\
\hline & \multirow[t]{2}{*}{ STDD (pss) } & 1.69 & 1.03 & 1.46 \\
\hline & & 1.69 & 1.01 & 1.46 \\
\hline & \multirow[t]{2}{*}{$r$} & 0.61 & 0.74 & 0.32 \\
\hline & & 0.61 & 0.75 & 0.32 \\
\hline & \multirow[t]{2}{*}{$\mathrm{N}$} & 3190 & 3190 & 3190 \\
\hline & & 3190 & 3190 & 3190 \\
\hline \multirow[t]{7}{*}{ Barents Sea } & \multirow[t]{2}{*}{$\mathrm{MoD}(\mathrm{pss})$} & -1.58 & -0.16 & -0.20 \\
\hline & & -1.58 & -0.15 & -0.20 \\
\hline & \multirow[t]{2}{*}{ STDD (pss) } & 0.95 & 0.93 & 0.49 \\
\hline & & 0.95 & 0.93 & 0.49 \\
\hline & \multirow[t]{2}{*}{$\mathrm{r}$} & -0.07 & -0.05 & 0.19 \\
\hline & & -0.07 & -0.05 & 0.19 \\
\hline & $\mathrm{N}$ & 10762 & 10762 & 10762 \\
\hline
\end{tabular}




\begin{tabular}{|c|c|c|c|c|}
\hline & & 10762 & 10762 & 10762 \\
\hline \multirow[t]{4}{*}{ Atlantic area } & MoD (pss) & $\begin{array}{l}-1.28 \\
\mathbf{- 1 . 2 8}\end{array}$ & $\begin{array}{l}-0.50 \\
-\mathbf{0 . 4 9}\end{array}$ & $\begin{array}{l}0.01 \\
\mathbf{0 . 0 1}\end{array}$ \\
\hline & STDD (pss) & $\begin{array}{l}0.99 \\
0.99\end{array}$ & $\begin{array}{l}1.10 \\
\mathbf{1 . 0 9}\end{array}$ & $\begin{array}{l}0.10 \\
\mathbf{0 . 1 0}\end{array}$ \\
\hline & $\mathrm{r}$ & $\begin{array}{l}0.02 \\
0.02\end{array}$ & $\begin{array}{l}-0.04 \\
-\mathbf{0 . 0 4}\end{array}$ & $\begin{array}{l}0.70 \\
\mathbf{0 . 7 0}\end{array}$ \\
\hline & $\mathrm{N}$ & $\begin{array}{l}2865 \\
\mathbf{2 8 6 5}\end{array}$ & $\begin{array}{l}2865 \\
\mathbf{2 8 6 5}\end{array}$ & $\begin{array}{l}2865 \\
\mathbf{2 8 6 5}\end{array}$ \\
\hline \multirow[t]{4}{*}{ Arctic Ocean } & MoD (pss) & $\begin{array}{l}-1.46 \\
\mathbf{- 1 . 4 6}\end{array}$ & $\begin{array}{l}-0.21 \\
-\mathbf{0 . 2 5}\end{array}$ & $\begin{array}{l}1.20 \\
\mathbf{1 . 2 0}\end{array}$ \\
\hline & STDD (pss) & $\begin{array}{l}1.31 \\
\mathbf{1 . 3 1}\end{array}$ & $\begin{array}{l}1.15 \\
\mathbf{1 . 1 5}\end{array}$ & $\begin{array}{l}1.86 \\
\mathbf{1 . 8 6}\end{array}$ \\
\hline & $\mathrm{r}$ & $\begin{array}{l}0.93 \\
\mathbf{0 . 9 3}\end{array}$ & $\begin{array}{l}0.95 \\
0.95\end{array}$ & $\begin{array}{l}0.89 \\
\mathbf{0 . 8 9}\end{array}$ \\
\hline & $\mathrm{N}$ & $\begin{array}{l}148655 \\
\mathbf{1 4 8 6 5 5}\end{array}$ & $\begin{array}{l}148655 \\
\mathbf{1 4 8 6 5 5}\end{array}$ & $\begin{array}{l}148655 \\
\mathbf{1 4 8 6 5 5}\end{array}$ \\
\hline
\end{tabular}

808

809 Appendix-G: example of differences recorded between $\mathrm{SSS}_{\mathrm{SMOS}} \mathrm{A}+\mathrm{T}$ using $\mathrm{SST}_{\text {REMSS }}$ or using 810 SST $_{\text {REMSS }}$ mwo in comparison of differences between $\mathrm{SSS}_{\mathrm{SMOS}}$ and $\mathrm{SSS}_{\mathrm{SMOS}} \mathrm{A}+\mathrm{T}$ (using

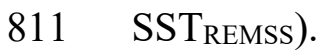


A

$\mathrm{SSS}_{\mathrm{SMOS} \mathrm{A+T}}$ (derived with $\mathrm{SST}_{\mathrm{REMSS}}$ ) - $\mathrm{SSS}_{\mathrm{SMOS}}$

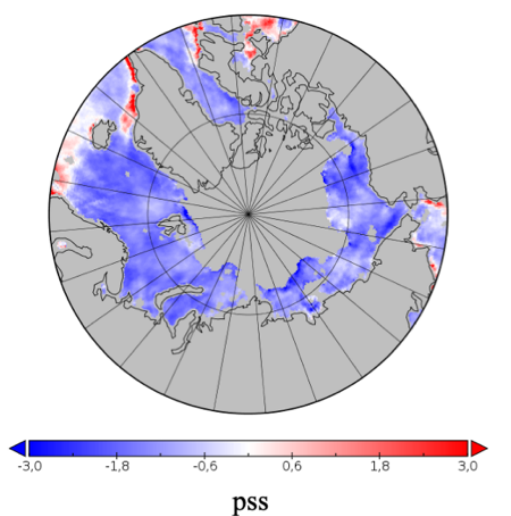

B

$\mathrm{SSS}_{\mathrm{SMOSA} \text { A T }}\left(\right.$ derived with $\left.\mathrm{SST}_{\text {REMSS }}\right)$

$\mathrm{SSS}_{\mathrm{SMOSA} \mathrm{A} \text { ( }}$ (derived with $\mathrm{SST}_{\mathrm{REMSS} \mathrm{MWO}}$ )

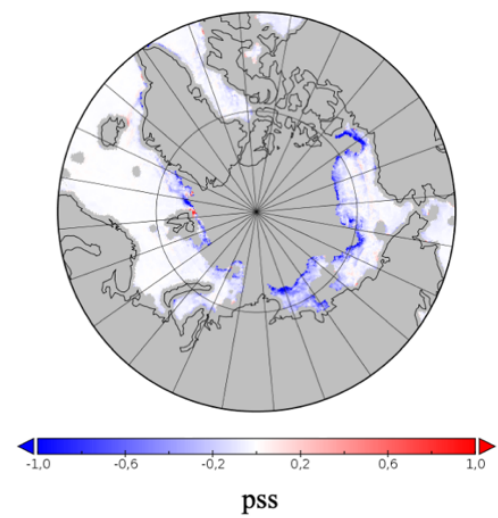

Figure G1: (A) difference between $\mathrm{SSS}_{\mathrm{SMOS}}$ and $\mathrm{SSS}_{\mathrm{SMOS}} \mathrm{A}+\mathrm{T}$ (computed using $\mathrm{SST}_{\mathrm{REMSS}}$ ) average for the period from August to October 2017; (B) difference between SSS SMOS A+T (computed using $\mathrm{SST}_{\mathrm{REMSS}}$ ) and $\mathrm{SSS}_{\mathrm{SMOS}} \mathrm{A}^{+\mathrm{T}}$ (computed using $\mathrm{SST}_{\mathrm{REMSS}} \mathrm{MwO}$ ) average for the period from August to October 2017.

812

813 Appendix-H: MoD, STDD, $\mathrm{r}$ and $\mathrm{N}$ (number of collocations) between different versions of

814 SMOS SSS or TOPAZ SSS and in-situ measurements for the different study areas. In black,

815 new SMOS SSS, in blue SMOS BEC v2 (Olmedo et al. 2018) and in red SMOS CEC v3 (Boutin 816 et al. 2018).

\begin{tabular}{|c|c|c|c|c|}
\hline Cases study & Statistic indicator & SSS $_{\text {SMOS }}$ & SSS $_{\text {SMOS A+T }}$ & SSS $_{\text {TOPAZ }}$ \\
\hline Beaufort Sea & MoD (pss) & -2.12 & -0.83 & 3.67 \\
& & $(1.04)$ & & \\
& & $(3.51)$ & & \\
\hline & STDD (pss) & 0.96 & 0.88 & 1.18 \\
& & $(1.85)$ & & \\
& & $(2.35)$ & & \\
& & & & \\
\hline
\end{tabular}




\begin{tabular}{|c|c|c|c|c|}
\hline & $\mathrm{r}$ & $\begin{array}{c}0.86 \\
(0.78) \\
(0.76)\end{array}$ & 0.88 & 0.86 \\
\hline & $\mathrm{N}$ & $\begin{array}{l}(3912) \\
(3976) \\
(4434)\end{array}$ & 3912 & 3912 \\
\hline \multirow[t]{4}{*}{ Chukchi Sea } & MoD (pss) & $\begin{array}{l}-1.50 \\
(0.53) \\
(3.00)\end{array}$ & -1.28 & 1.97 \\
\hline & STDD (pss) & $\begin{array}{l}1.47 \\
(1.48) \\
(1.87)\end{array}$ & 1.23 & 1.78 \\
\hline & $\mathrm{r}$ & $\begin{array}{c}0.84 \\
(0.83) \\
(0.54)\end{array}$ & 0.88 & 0.86 \\
\hline & $\mathrm{N}$ & $\begin{array}{l}(90721) \\
(100908) \\
(105986)\end{array}$ & 90721 & 90721 \\
\hline \multirow[t]{2}{*}{ Laptev Sea } & MoD (pss) & $\begin{array}{l}-1.97 \\
(0.37) \\
(0.59)\end{array}$ & 0.11 & 1.51 \\
\hline & STDD (pss) & 1.82 & 1.17 & 1.89 \\
\hline
\end{tabular}




\begin{tabular}{|c|c|c|c|c|}
\hline & & $\begin{array}{l}(1.85) \\
(2.35)\end{array}$ & & \\
\hline & $\mathrm{r}$ & $\begin{array}{c}0.53 \\
(0.39) \\
(-0.10)\end{array}$ & 0.75 & 0.04 \\
\hline & $\mathrm{N}$ & $\begin{array}{l}(4048) \\
(3391) \\
(3391)\end{array}$ & 4048 & 4048 \\
\hline \multirow[t]{4}{*}{ Barents Sea } & $\mathrm{MoD}$ (pss) & $\begin{array}{c}-1.59 \\
(-0.01) \\
(0.35)\end{array}$ & -0.17 & -0.19 \\
\hline & STDD (pss) & $\begin{array}{c}0.96 \\
(0.88) \\
(1.39)\end{array}$ & 0.94 & 0.50 \\
\hline & $\mathrm{N}$ & $\begin{array}{l}(10879) \\
(15571) \\
(18622)\end{array}$ & 10879 & 10879 \\
\hline & $\mathrm{r}$ & $\begin{array}{l}-0.03 \\
(0.31) \\
(-0.14)\end{array}$ & -0.04 & 0.19 \\
\hline Atlantic Area & $\mathrm{MoD}(\mathrm{pss})$ & $\begin{array}{l}-1.29 \\
(0.01)\end{array}$ & -0.51 & 0.01 \\
\hline
\end{tabular}




\begin{tabular}{|c|c|c|c|c|}
\hline & & $(0.01)$ & & \\
\hline & STDD (pss) & $\begin{array}{l}1.02 \\
(0.27) \\
(0.66)\end{array}$ & 1.13 & 0.10 \\
\hline & $\mathrm{r}$ & $\begin{array}{c}0.01 \\
(0.38) \\
(-0.05)\end{array}$ & -0.05 & 0.70 \\
\hline & $\mathrm{N}$ & $\begin{array}{l}(2876) \\
(5863) \\
(6168)\end{array}$ & 2876 & 2876 \\
\hline Arctic Ocean & MoD (pss) & $\begin{array}{l}-1.54 \\
(0.12) \\
(1.55)\end{array}$ & -0.27 & 1.25 \\
\hline & STDD (pss) & $\begin{array}{c}1.46 \\
(1.65) \\
(2.30)\end{array}$ & 1.28 & 1.86 \\
\hline & $\mathrm{r}$ & $\begin{array}{c}0.92 \\
(0.93) \\
(0.86)\end{array}$ & 0.94 & 0.89 \\
\hline & $\mathrm{N}$ & $\begin{array}{l}(156986) \\
(196665) \\
(225904)\end{array}$ & 156986 & 156986 \\
\hline
\end{tabular}


817

818

819 